\title{
Nanostructured high-entropy materials
}

\author{
Michel J.R. Haché $e^{1}$ Changjun Cheng ${ }^{1}$, Yu Zou ${ }^{1, a)}$ (1) \\ ${ }^{1}$ Department of Materials Science and Engineering, University of Toronto, Toronto, ON M5S 3E4, Canada \\ ${ }^{a)}$ Address all correspondence to this author. e-mail: mse.zou@utoronto.ca \\ This paper has been selected as an Invited Feature Paper. \\ Received: 9 November 2019; accepted: 16 January 2020
}

In the past decade, the emergence of high-entropy alloys (HEAs) and other high-entropy materials (HEMs) has brought about new opportunities in the development of novel materials for high-performance applications. In combining solid-solution (SS) strengthening with grain-boundary strengthening, new material systemsnanostructured or nanocrystalline (NC) HEAs or HEMs-have been developed, showing superior combined mechanical and functional properties compared with conventional alloys, HEAs, and NC metals. This article reviews the processing methods, materials, mechanical properties, thermal stability, and functional properties of various nanostructured HEMs, particularly NC HEAs. With such new nanostructures and alloy compositions, many interesting phenomena and properties of such NC HEAs have been unveiled, for example, extraordinary microstructural and mechanical thermal stability. As more HEAs or HEMs are being developed, a new avenue of research is to be exploited. The article concludes with perspectives about future directions in this field.

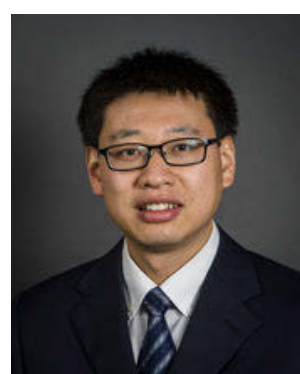

Yu Zou

Yu Zou is a Dean's Spark Assistant Professor in the Department of Materials Science and Engineering at the University of Toronto. Before joining the University of Toronto in 2018, he was a postdoctoral fellow in the Department of Mechanical Engineering at Massachusetts Institute of Technology (MIT), working on laserbased metal additive manufacturing with Prof. A. John Hart. He received his Doctor of Sciences in Materials from ETH Zurich in 2016 with Prof. Ralph Spolenak. His doctoral thesis focused on small-scale plasticity of ionic crystals, HEAs, and quasicrystals. He was also a JSPS visiting scholar at Kyoto University in 2014, working on in situ nanomechanical testing with Prof. Takayuki Kitamura. He received his master's and bachelor's degrees from McGill University and Beihang University, respectively, all in materials science and engineering. At McGill, he worked on cold sprayed metallic coatings with Profs. Jerzy Szpunar and Stephen Yue. He currently directs the Laboratory for Extreme Mechanics \& Additive Manufacturing (LEMAM) at the University of Toronto. His group seeks to develop novel experimental, simulation, and analytical methods to explore new metallic materials and advance fields of vital importance to society, including the aerospace, biomedical, and energy sectors. Currently, his group has four primary emphases: (i) new nanostructure alloys, (ii) multiscale mechanical testing, (iii) multimetal additive manufacturing, and (iv) high-throughput experimentation. At the University of Toronto, he has been awarded Connaught New Researcher Award and Dean's Spark Professorship.

\section{Introduction}

High-entropy alloys (HEAs) have attracted great attention in the academy over the last 15 years, as many useful and unique properties have been discovered from such materials with a high degree of configurational entropy [1]. HEAs are generally described as alloys comprising five or more elements in a compositional range of 5-35 at.\% each, generally forming a single solid-solution (SS) phase. Other terms such as multiprincipal element alloys (MPEAs), complex concentrated alloys (CCAs), and high-entropy materials (HEMs) are generally used to describe the broader range of multicomponent alloys, including multiphase HEAs, which are not restricted to single-phase formation $[2,3]$.

Nanocrystalline (NC) materials, with their grain size $<100 \mathrm{~nm}$, have brought both scientific and technical interests since the 1980s, especially NC metals and alloys [4]. In NC materials, it is the grain boundaries, rather than their compositions, that influence their mechanical and functional properties substantially, for example, enhanced material strength by grain refinement has seen much success over the past three decades $[4,5]$. However, the current limitation that restricts the use of NC metals in elevated, and even moderate, temperature 
environments is their poor thermal stability, as grains dramatically coarsen with time. Some early studies suggested that alloying may stabilize nanometer-sized grains, improving the thermal stability of NC metals and providing additional strength through combined grain-boundary and SS strengthening mechanisms [6, 7]. It is from this theory that the progression from single crystals to NC metals to NC HEAs [Fig. 1(a)] in recent literature has emerged.

Combining the alloying and grain-size effects, NC and nanostructured HEMs have attracted much attention over the past five years. This article outlines the progress in this field and assesses the current state of validation of entropy-based stabilization theories. Synthesis processes, types of materials, mechanical properties, thermal stability, and a few functional properties will be reviewed. This article will provide insight into the most recent advancements in HEMs and identify the gaps in knowledge and direction, in which novel HEM research may progress rapidly in the future.

\section{Core effects in HEAs}

Four core effects characterizing the behavior of HEAs were initially proposed by Yeh in 2006 [8]: high-entropy, sluggish diffusion, severe lattice distortion, and "cocktail" effects. As shown in Fig. 1, the ultimate source of such effects stems from either size mismatch (i.e., the difference in atomic radii) or the quantity of alloying elements. The resultant properties are amplified lattice-sensitive properties, slower kinetics, and enhanced stability of SS phases. Contrarily, the cocktail effect describes the innate complexity of trying to anticipate the properties of a configurationally complex alloy. Collectively, these four effects can be used to predict mechanical and functional properties that certain compositions of HEAs can exhibit. These effects are discussed in further detail in the literature $[2,3]$.

\section{Thermodynamics of phase formation in HEAs}

Phase formation in HEAs is predominantly governed by a competition between the stability of SS and intermetallic (IM) phases. Although it is typically desirable to avoid IM phases because of their inherent brittleness, in CCAs, this is often difficult because of the heightened number of compositional degrees of freedom, as described by the Gibbs phase rule. The Gibbs free energy of a given phase $\phi$ is calculated as [2]

$$
G^{\phi}=H^{\phi}-T S^{\phi} .
$$

In this case, we consider the phase $\phi$ as either SS or IM. From this equation, the more stable phase will be one that best balances the minimization of enthalpy and maximization of entropy. It is from this balance that the competition between SS and IM phase formation is apparent.

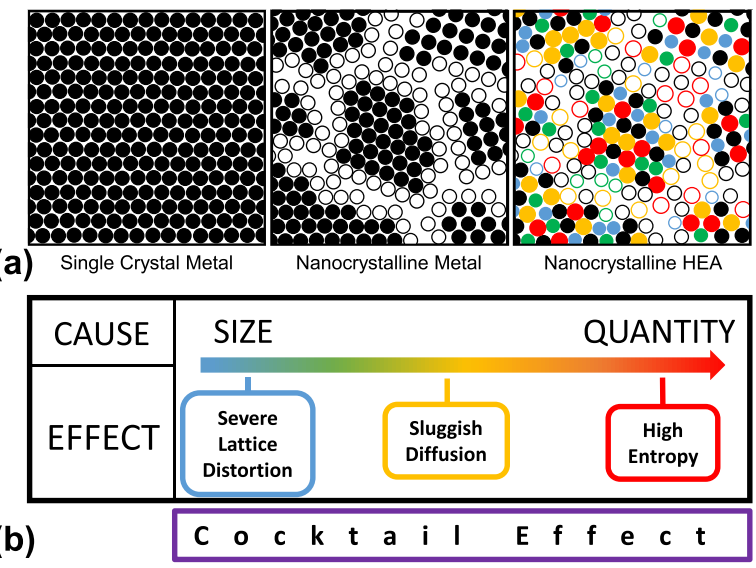

Figure 1: (a) Microstructural schematic of the progression from single crystal metals to NC metals to NC HEAs and (b) core effects of HEAs proposed by Yeh [8]. The hollow and solid circles represent atoms that lie on grain boundaries and within grains, respectively.

\section{Strengthening mechanisms in HEAs}

\section{Solid-solution strengthening}

As a cornerstone of HEA development, SS strengthening is an effective mechanism by which the strength of materials can be increased. Strengthening results from the pinning of dislocations due to local lattice strain within the grains of a material. Lattice strain arises from an atomic radius and elastic modulus mismatch between the constituent elements. Modeling of the strengthening contribution from the addition of solute atoms $\left(\Delta \sigma_{\mathrm{SS}}\right)$ in dilute binary systems has been extensively studied, with the most widely accepted models being those proposed by Fleischer [9] and Labusch [10], which are expressed as

$$
\Delta \sigma_{\mathrm{SS}}=B_{i} X_{i}^{\frac{1}{c}}
$$

where $\Delta \sigma_{\mathrm{SS}}$ is the increase in yield strength, $c$ a constant (typically around 2-3), $X_{i}$ the solute concentration (in atomic fraction), and $B_{i}$ a hardening parameter dependent on the atomic mismatch, shear modulus, and elastic misfit.

However, HEA systems are much more complex than binary alloys because of enhanced interactions between different atoms in the crystal lattice. Few models have been proposed to accurately describe the SS strengthening behavior in multicomponent alloys. Early attempts by Gypen and Deruyttere [11] made assumptions that solutes within the material do not interact with one another. The issue with this model is that the atomic size misfit that exists in the continuously deformed matrix of HEAs is not considered, making it only applicable to multicomponent alloys compositionally dominated by a single element. The most recent model by Toda-Caraballo and Rivera-Díaz-del-Castillo [12] builds on the Labusch model and demonstrates a good fit to experimental data. Their model goes beyond that of other attempts, taking into account 
a number of effects unique to HEAs [12]. The HEA SS strengthening effect, $\Delta \sigma_{\mathrm{SS}, \mathrm{HEA}}$, can thus be modeled by

$$
\Delta \sigma_{\mathrm{SS}, \mathrm{HEA}}=\left(\sum_{i} B_{i, L}^{\frac{3}{2}} X_{i}\right)^{2 / 3}
$$

where $B_{i}$ is calculated in the same way as in the Labusch model. From this relationship, we anticipate a pronounced strengthening effect in HEAs compared with "conventional" binary alloy systems.

\section{Grain-boundary strengthening}

Grain-boundary strengthening is one of the most widely studied strengthening mechanisms. The premise behind it is the enhanced impingement of dislocation motion through the introduction of more grain boundaries within a material (i.e., decreasing grain size). The relationship between yield strength $\left(\sigma_{\mathrm{y}}\right)$ and grain size $(D)$ is known as the Hall-Petch (H-P) relationship $[13,14]$ :

$$
\sigma_{\mathrm{y}}=\sigma_{\mathrm{o}}+k_{\mathrm{y}} D^{-\frac{1}{2}},
$$

where $\sigma_{\mathrm{o}}$ is the overall resistance of the lattice to dislocation motion and $k_{\mathrm{y}}$ is a constant related to the relative hardening contribution of grain boundaries [15]. As Eq. (4) suggests, when the average grain size of a material is decreased, its strength increases. This relationship is the major driving force behind the development of NC materials (defined in this article as materials with a grain size $<100 \mathrm{~nm}$ ), where this effect becomes further enhanced at very low values of $D$ because of the inverse-square root relationship. However, this relationship tends to break down at very small grain sizes, typically around 10-20 nm. At this point, an inverse H-P relationship takes over, in which pronounced softening takes place with decreasing grain size. The mechanisms underlying the inverse $\mathrm{H}-\mathrm{P}$ effect include dislocation- or diffusion-induced grainboundary shearing and sliding, grain rotation, and two-phasebased models [16]. Because of its complex nature, the inverse $\mathrm{H}-\mathrm{P}$ effect will not be further discussed in this article, which will instead only explore the mechanical properties and deformation mechanisms of materials in the grain size range $\sim 10-100 \mathrm{~nm}$.

\section{Coupling grain-boundary strengthening with the high-entropy effect}

To make these NC materials more universally functional across engineering systems, many studies have focused on devising methods to stabilize such small grains over larger temperature and time scales. In determining the methods by which we can effectively stabilize NC grains, we must first outline the thermodynamic parameters that affect grain growth. The rate of grain growth can be represented thermodynamically by the grain-boundary velocity, $v_{\mathrm{g}}$, which is the product of the grainboundary mobility $\left(M_{\mathrm{g}}\right)$ and the difference in total driving $\left(F_{\mathrm{t}}\right)$ and drag $\left(F_{\mathrm{d}}\right)$ forces acting on a grain [17], as expressed by Eq. (5).

$$
v_{\mathrm{g}}=M_{\mathrm{g}}\left(F_{\mathrm{t}}-F_{\mathrm{d}}\right)
$$

The total driving force can be contributed to by many factors, including stored deformation energy, grain-boundary energy, surface energy, chemical driving force, magnetic field, elastic energy, and temperature gradients [17]. In NC materials, the driving force for a reduction in grain-boundary energy $\left(F_{\mathrm{g}}\right)$ is often the dominating term in $F_{\mathrm{t}}$ because of their small grain size. This driving force is calculated using the following equation:

$$
F_{\mathrm{g}}=\frac{2 \gamma}{D}=\frac{\Delta G}{V_{\mathrm{m}}}
$$

which is also known as the Gibbs-Thompson equation [18]. According to Eq. (5), there are three possible ways of stabilizing grains: decreasing the driving force, decreasing the mobility, and increasing the drag force. In NC HEAs, although the grain size $(D)$ is very small, the effective grain-boundary energy $(\gamma)$ is inherently low compared with conventional alloy classes, leading to a decrease in the driving force [6]. This is due to a combination of segregation of solutes along boundaries and heightened energy levels in the distorted matrix compared with a matrix of pure metal. In terms of mobility, the probability of an atom successfully "jumping" across a grain boundary is lower because of the configurational complexity and the need for coordinated movement of different atoms. Lastly, high diffusivity along grain boundaries compared to the bulk diffusivity can lead to pronounced localized segregation of certain elements, which increases the drag force. The overall combined effect should result in a lower rate of grain growth upon heating in HEAs than conventional materials with similar melting points. Such results have been reported in $3 \mathrm{~d}$ transition and refractory metal HEAs [19, 20, 21, 22], which will be discussed further in the following sections.

\section{Methods to prepare NC HEAs}

There are many methods of preparing NC materials for various applications, length-scale capabilities, energy requirements, and capital costs. Table I lists the advantages and disadvantages of each NC-material synthesis category. Although there are other unique synthesis methods, we can generally classify them into one of these categories.

Of these synthesis methods, mechanical alloying (MA), thermal spraying, and electrodeposition are the most 
TABLE I: Advantages and disadvantages of five major classes of NC material synthesis techniques.

\begin{tabular}{|c|c|c|}
\hline Method & Advantages & Disadvantages \\
\hline $\begin{array}{l}\text { Mechanical alloying [146] } \\
\text { Ball-milling and cryo-milling }\end{array}$ & $\begin{array}{l}\text { - Scalable } \\
\text { - No melting required } \\
\text { - Allows alloying of normally immiscible elements }\end{array}$ & $\begin{array}{l}\text { - Rapid grain growth upon consolidation of powders } \\
\text { - Void formation on compaction and sintering } \\
\text { - High energy input } \\
\text { - High risk of contamination } \\
\text { - Large variation in particle size }\end{array}$ \\
\hline $\begin{array}{l}\text { Thermal spraying [147] } \\
\text { Cold-spray, plasma-spray, flame-spray, } \\
\text { etc. . }\end{array}$ & $\begin{array}{l}\text { - High deposition rate } \\
\text { - Near-net-shape coating technology } \\
\text { - Scalable } \\
\text { - No thickness limitations } \\
\text { - High deposition rate }\end{array}$ & $\begin{array}{l}\text { - Voids } \\
\text { - Constrained geometry } \\
\text { - High equipment cost } \\
\text { - High energy input } \\
\text { - Nonuniform grain-size distribution }\end{array}$ \\
\hline $\begin{array}{l}\text { Gas condensation, DC/RF sputtering, } \\
\text { vacuum arc deposition }\end{array}$ & $\begin{array}{l}\text { - Wide range of materials can be } \\
\text { synthesized } \\
\text { - Good control of cluster sizes } \\
\text { - Continuous process } \\
\text { - Low risk of contamination } \\
\text { - Low thermal load to substrate } \\
\text { - High coating density and adhesion } \\
\text { - Excellent uniformity }\end{array}$ & $\begin{array}{l}\text { - Void formation upon compaction and sintering of vapor- } \\
\text { deposited powders } \\
\text { - High cost (need ultra-high vacuum) } \\
\text { - Difficult to scale up (low yield) } \\
\text { - Requires vacuum environment } \\
\text { - Limited to thin films }\end{array}$ \\
\hline $\begin{array}{l}\text { Severe plastic deformation [23] } \\
\text { High pressure torsion, equal channel } \\
\text { angular pressing }\end{array}$ & $\begin{array}{l}\text { - Straightforward relationship between strain and } \\
\text { grain size } \\
\text { - Simple grain-refinement mechanism }\end{array}$ & $\begin{array}{l}\text { - Small-scale } \\
\text { - Constrained geometry } \\
\text { - Poor efficiency } \\
\text { - High waste }\end{array}$ \\
\hline Electrodeposition [149] & $\begin{array}{l}\text { - Low cost } \\
\text { - Low energy requirements } \\
\text { - Scalable } \\
\text { - Can obtain uniform grain sizes } \\
\text { - Few size or shape limitations } \\
\text { - Low initial capital investment }\end{array}$ & $\begin{array}{l}\text { - Difficult to co-deposit multiple elements } \\
\text { - Constrained to certain elements } \\
\text { - Significant internal stresses can be built up in the material }\end{array}$ \\
\hline
\end{tabular}

industrially scalable, which are potentially able to produce large volumes of NC materials within a reasonable time frame. Scalability studies surrounding combined severe plastic deformation (SPD) techniques have been performed, with samples more than $800 \mathrm{~mm}$ in length and $6.5 \mathrm{~mm}$ in diameter [23]. However, the large-scale adoption of these techniques is currently not existent. Although they have much higher operating costs, vapor deposition techniques can yield very uniform and contamination-free NC metals as a result of their well-controlled and isolated working environment.

We can also investigate the popularity of each method as it relates specifically to the synthesis of NC HEAs, as shown in Fig. 2. MA is the most popular synthesis method in literature, followed by high-pressure torsion (HPT) and physical vapor deposition (PVD) processes. Through all synthesis routes, most popular HEAs studied to date are from the $3 \mathrm{~d}$ transition metal category, such as CoCrFeNiMn.

The major benefit of MA is its incredible versatility. Any material that can be made in a powder form could be refined using this method $[22,24,25,26,27]$. The ease of use of the MA equipment is another advantage compared with more complex systems, such as PVD and electrodeposition. However, the most predominant issue in MA arises from the need to consolidate the refined NC powders into a bulk material, which is usually done through spark plasma sintering (SPS). Although long milling times $(\sim 40 \mathrm{~h})$ for $3 \mathrm{~d}$ transition metals can yield single-phase materials with grain sizes typically around $20 \mathrm{~nm}$, and as low as $5 \mathrm{~nm}$, the preparation of a bulk specimen from these powders dramatically coarsens the grain structure to beyond $500 \mathrm{~nm}$ in some cases [28, 29, 30]. Another disadvantage of the MA method is the contamination that can occur during the preparation process, in which the cylinder walls can contaminate HEA compositions.

Although grain refinement of $3 \mathrm{~d}$ transition HEAs through HPT is typically limited to average grain sizes near $50 \mathrm{~nm}$, and as low as $10 \mathrm{~nm}[31,32]$, this method is more suitable for producing bulk specimens that do not need further processing, and hence such NC HEAs do not suffer from grain coarsening as those made by MA. Conversely, the major disadvantages of HPT stem from the scalability of the process. When considering the long-term goal of producing large-scale NC HEAs or even simply NC materials, HPT and other SPD methods require extensive process optimization before they can become industrially viable.

Finally, the third most popular synthesis method is DC magnetron sputtering (DCMS). The major advantage of this method is its versatility in being able to produce an alloy from nearly any combination of elements $[33,34,35]$. For this 


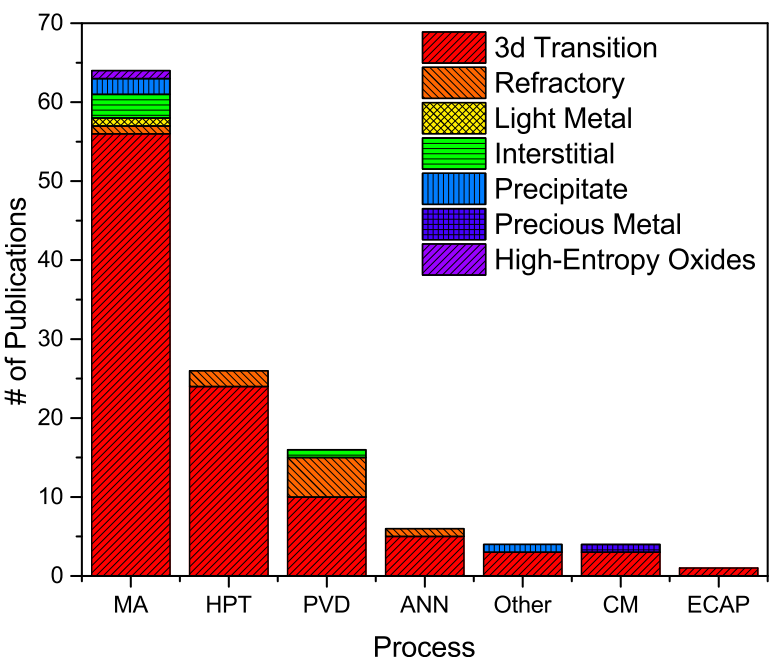

Figure 2: Distribution of synthesis methods and HEA classification (as described by Miracle and Senkov [2]) used in the NC-HEA literature (MA: mechanical alloying, HPT: high-pressure torsion, PVD: physical vapor deposition, ANN: annealed, CM: cryo-milling, ECAP: equal channel angular pressing, and other: sol-gel processing, flame spray pyrolysis, cold rolling, and melt spinning).

reason, we see that most of the work done on the refractory and interstitial classes of NC HEAs was accomplished by DC magnetron co-sputtering. Another advantage is the very small and uniform grain size that can be produced by this method, with an average of approximately $10 \mathrm{~nm}$ in $3 \mathrm{~d}$ transition metal HEAs [36]. The limitation of this method is that only thin films (thickness up to $1-5 \mu \mathrm{m}$ ) can be produced. Thus, it is often difficult to accurately determine the material's mechanical properties through conventional testing methods. This also limits the potential applications of materials made through this route, as the relatively niche market of thin films for mechanical applications suggests PVD is most applicable as a proof-of-concept driven technique rather than an industrially viable one.

\section{Materials for NC HEAs}

To date, the $3 \mathrm{~d}$ transition metal class has been the most popular NC-HEA class. Within the $3 \mathrm{~d}$ transition metals, we can generally identify two subclasses: Al-containing and nonAl-containing. The most common HEAs in these two classes are $\mathrm{AlCoCrFeNi}$ and $\mathrm{CoCrFeNiMn}$ alloys, respectively. In many cases, additional non-3d-transition metal elements other than $\mathrm{Al}$ have been added, such as $\mathrm{Ti}, \mathrm{Mg}, \mathrm{Mo}$, and $\mathrm{Nb}$, each with their own unique intent toward affecting the material properties of the HEAs. Figure 3 shows the distribution of crystal structures across publications relating to the synthesis of 3d transition metal NC HEAs.

There is no considerable preference in phase formation in both MA and DCMS processed NC HEAs, with a nearly even split between single-phase and multiphase materials in both $\mathrm{Al}$ and non-Al-containing $3 \mathrm{~d}$ transition alloys. By contrast, the HPT process, although it has a smaller sample size than MA, shows a much stronger tendency to form single SS phases, particularly in the CoCrFeNiMn alloys. We also see that the average grain size that can be achieved varies across the three synthesis routes, from $10 \mathrm{~nm}$ in DCMS to $18-20 \mathrm{~nm}$ in MA, and $33-53 \mathrm{~nm}$ in HPT. As deformation-based techniques, MA and HPT require that a significant amount of plastic deformation be applied to the material to achieve nanoscale grain sizes. Specifically, the lowest grain sizes $(\sim 5-10 \mathrm{~nm})$ in ballmilled HEAs have been obtained after milling times exceeding $20 \mathrm{~h}$ (using a planetary ball milling machine), which also tends to promote the formation of a single SS phase [28, 37]. For HPT, grain sizes as low as $10 \mathrm{~nm}$ have been achieved at shear strains of 420 (equal to 10 revolutions) and pressure of $5 \mathrm{GPa}$ [38]. By contrast, extremely low grain sizes in the order of $10 \mathrm{~nm}$ are characteristically acquired through DCMS, providing a much more uniform size distribution than those made by deformation-based methods.

As mentioned in section "Methods to prepare NC HEAs", NC-refractory HEAs have been much less explored than $3 \mathrm{~d}$ transition metals, likely because they are generally more expensive and difficult to process. As a result, they are most often fabricated as coatings and thin films via a PVD process (i.e., DCMS or vacuum arc deposition). These coatings will generally exhibit a BCC SS structure when comprised of the core refractory elements ( $\mathrm{Nb}, \mathrm{Mo}, \mathrm{Ta}$, and $\mathrm{W})$ [19, 33, 39], and can even form FCC structures in alloys such as TiVZrNbHf [40, 41]. Compared with $3 \mathrm{~d}$ transition HEAs, the grain sizes that can be achieved in these alloys are much larger, typically in the range of 40-50 nm. Processing via HPT does not affect this average grain size range and has been used to produce singlephase BCC HEAs by Schuh et al. [42, 43].

The synthesis of NC HEAs from other material classes such as interstitial, light metal, and precious metal alloys have been explored as well. There are no distinct trends in processing routes, phase formation, or grain sizes within these subclasses, but a few interesting features of some of such HEAs have been examined. Interstitial HEAs are of great interest because of the innate SS hardening that can be achieved by very small additions of elements such as nitrogen and carbon to $3 \mathrm{~d}$ transition metals. The unintended effect that comes up often, in this case, is the formation of precipitate phases, which can also act to strengthen the material, although through the separate mechanism of precipitate-hardening. These NC-interstitial HEAs tend to form either precipitates (which can be nanosized) $[22,44]$ or dual-phase structures (FCC + BCC) [35]. There has only been one report of light-metal NC-HEA production, achieved in an AlLiMgScTi alloy produced via ball-milling by Youssef et al. [27], with an average grain size 


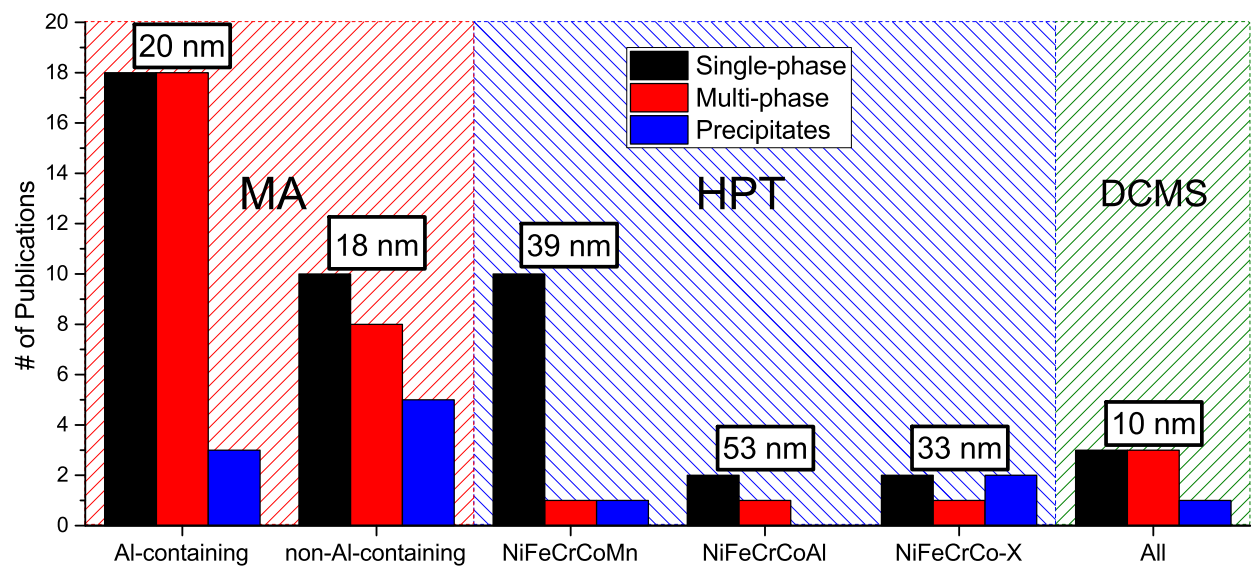

Figure 3: Phase formation tendencies in $3 d$ transition NC HEAs processed via MA, HPT, and DCMS. Multiphase alloys are made up of a combination of FCC, BCC, and/or HCP phases. Precipitates generally refer to IM compounds. The average grain size achieved by each process for each material class is highlighted above in their respective columns.

down to $12 \mathrm{~nm}$ and hardness of $5.8 \mathrm{GPa}$. Similarly, precious metals have rarely been explored, although Kumar et al. [26] have produced a CuAgAuPtPd with a grain size of $9 \mathrm{~nm}$ via cryo-milling. However, the exact intended application of this alloy is currently unclear.

\section{Mechanical properties of NC HEAs}

The development of $3 \mathrm{~d}$ transition metal HEAs is driven by the desire to replace conventional stainless steels and Ni-based superalloys. Of primary interest are the mechanical properties of such NC HEAs as a function of grain size and their thermal stability over large temperature and time ranges.

As shown in Fig. 4(a), there is a wide range of hardness values that can be achieved in NC HEAs, with no distinct trends as a function of grain size. Generally, NC-3d transition HEAs fall within hardness ranges of 400-700 HV. In comparison with conventional materials such as 304 stainless steel $(660 \mathrm{MPa}$ tensile strength, $\sim 200 \mathrm{HV}[66]$ ) and Inconel 600 (660 tensile strength, $\sim 200 \mathrm{HV}[66]$ ), the hardness of the $3 \mathrm{~d}$ transition metal class exceeds $\sim 400 \mathrm{HV}$ at all grain sizes below $150 \mathrm{~nm}$. However, insight into the toughness, ductility, and work hardening characteristics of these HEAs is currently lacking.

Figure 4(b) presents the hardness measured using instrumented indentation. As this testing technique continuously measures the depth and load throughout indentation, the reported results are more readily comparable to more common testing procedures such as tensile and compression testing. For these HEAs, there is no distinct trend with varying grain size. Most HEAs fall in the range of 5-9 GPa, indicated by the red hatched box.

For refractory HEAs, Firstov et al. [40] and Sobol' et al. [41] have synthesized NC-TiVZrNbHf nitride coatings, achieving hardness values of 64 and $70 \mathrm{GPa}$, respectively. The core group of refractory elements, NbMoTaW, exhibits high hardness with nanoscale structure, falling in the hardness range of 12-16 GPa $[33,39]$. In comparison to $3 \mathrm{~d}$ transition HEAs, the refractory class generally exhibits higher hardness. The NbMoTaW alloy has also been shown to have incredible thermal stability by Zou et al. [19], which will be discussed in section "Microstructure and mechanical stability".

\section{Hall-Petch effect}

Characteristics of the $\mathrm{H}-\mathrm{P}$ effect can be distinctly different between different alloy compositions. Figure 5(a) shows that although many different materials may have similar friction stresses $\left(\sigma_{\mathrm{o}}\right)$, there are large differences in their $k_{\mathrm{y}}$ constants (a constant related to the relative hardening contribution of grain boundaries). We observe a trend that, in general, as the number of elements is increased in an alloy, there is an increase in the slope of the H-P relation $\left(k_{\mathrm{y}}\right)$. This value is related to the grainboundary surface energy of the material, which we have already established is inherently low in HEAs [15]. Stacking fault energy (SFE) also affects the H-P constant [Fig. 5(b)], as a lower SFE promotes the formation of subboundaries which are more resistant to dislocation motion [18]. Zaddach et al. [68] have demonstrated using a combined experimental and DFT-based computational approach that the SFE can be significantly decreased with the addition of principal elements into the matrix, decreasing from $\sim 125 \mathrm{~mJ} / \mathrm{m}^{2}$ in pure $\mathrm{Ni}$ to $\sim 20 \mathrm{~mJ} / \mathrm{m}^{2}$ in equiatomic CoCrFeNiMn. Furthermore, the slightest variance from an equiatomic composition can drastically alter the SFE, with values ranging from $57.7 \mathrm{~mJ} / \mathrm{m}^{2}$ in $\mathrm{Co}_{20} \mathrm{Cr}_{14} \mathrm{Fe}_{20} \mathrm{Ni}_{26} \mathrm{Mn}_{20}$ down to $3.5 \mathrm{~mJ} / \mathrm{m}^{2}$ in $\mathrm{Co}_{20} \mathrm{Cr}_{26} \mathrm{Fe}_{20} \mathrm{Ni}_{14} \mathrm{Mn}_{20}$.

Although none of the HEAs presented in Fig. 5 are NC, it gives insight into a supposed improved hardenability that can 
be achieved in decreasing grain sizes of HEAs to the nanoscale compared with more dilute alloys.

\section{Wear resistance}

The wear resistance of all materials is closely related to their hardness, represented by the following steady-state wear equation [75]:

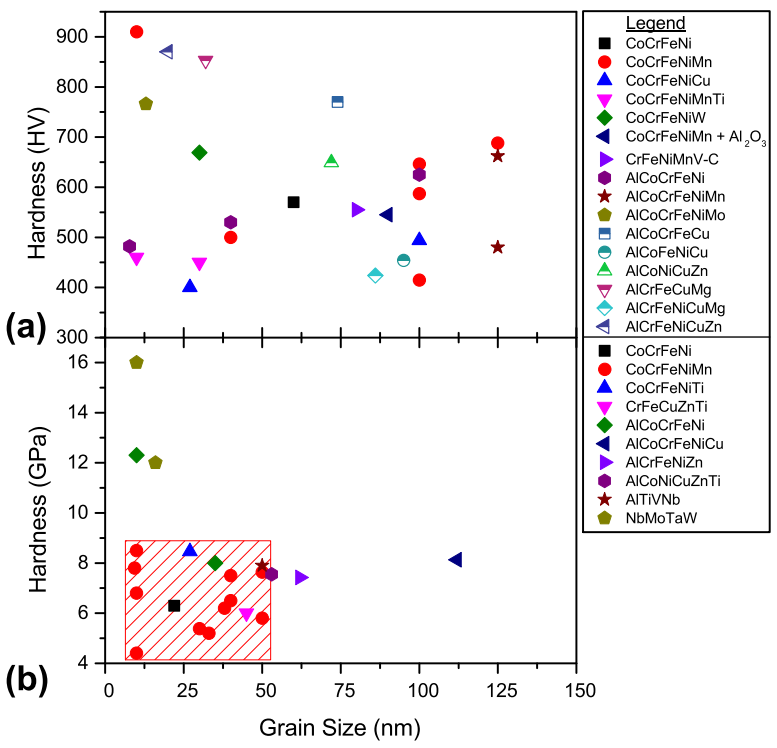

Figure 4: Hardness as a function of grain size for NC-3d transition HEAs: (a) Vicker's micro-hardness (HV) and (b) instrumented indentation hardness. The shaded region in (b) shows the rough bounds which most NC HEAs, including all CoCrFeNiMn, fall within. Data were collected from Refs. 28, 29, 30, 32, 43, $44,45,46,47,48,49,50,51,52,53,54,55,56,57,58,59,60,61,62,63,64$, and 65.

$$
V=K \frac{P L}{3 H}
$$

where $V$ and $L$ are the volumetric loss and sliding distance, respectively. $K$ is a dimensionless net steady-state wear coefficient and $H$ the Brinell hardness. In general, materials with high hardness typically exhibit high wear resistance. For materials of similar hardness, the wear coefficient $K$ is also a good comparative standard for wear resistance.

As a major component in many high-performance industrially used alloys, the CoCrFeNi system is an ideal base for HEAs. However, its intrinsic hardness is relatively low $(\sim 106$ HV) because of its FCC structure [1, 76, 77, 78, 79]. As previously established, a reduction in the grain size is an effective method of improving the mechanical performance of a material. The production of a $\mathrm{NC}-\mathrm{CoCrFeNi}$ alloy through MA and vacuum hot-pressing sintering (VHPS) has been used to achieve $30-\mathrm{nm}$ grain sizes, resulting in higher hardness values $(450 \mathrm{HV})$ and a low friction coefficient (0.38) [80]. Another method frequently used to strengthen materials is precipitation hardening, in which small-scale hard phases can help to impede dislocation motion throughout the lattice through a mechanism known as Zener pinning. Following this Zener pinning mechanism, the addition of hard metallic elements from the refractory group such as Mo and $\mathrm{W}$ to $3 \mathrm{~d}$ transition metal HEA matrices have been shown to significantly improve the hardness and wear resistance [51]. However, contrary to this theory, $\mathrm{Cu}$-rich FCC nanoprecipitates in the $\mathrm{CoCrFeNiCu}$ system yield lower hardness ( $\sim 400 \mathrm{HV})$ and a large friction coefficient (0.6). This suggests that $\mathrm{Cu}$-comprising precipitates are generally soft and do not promote the Zener pinning mechanism. Therefore, such NC HEAs are not very useful for wear resistance [80].
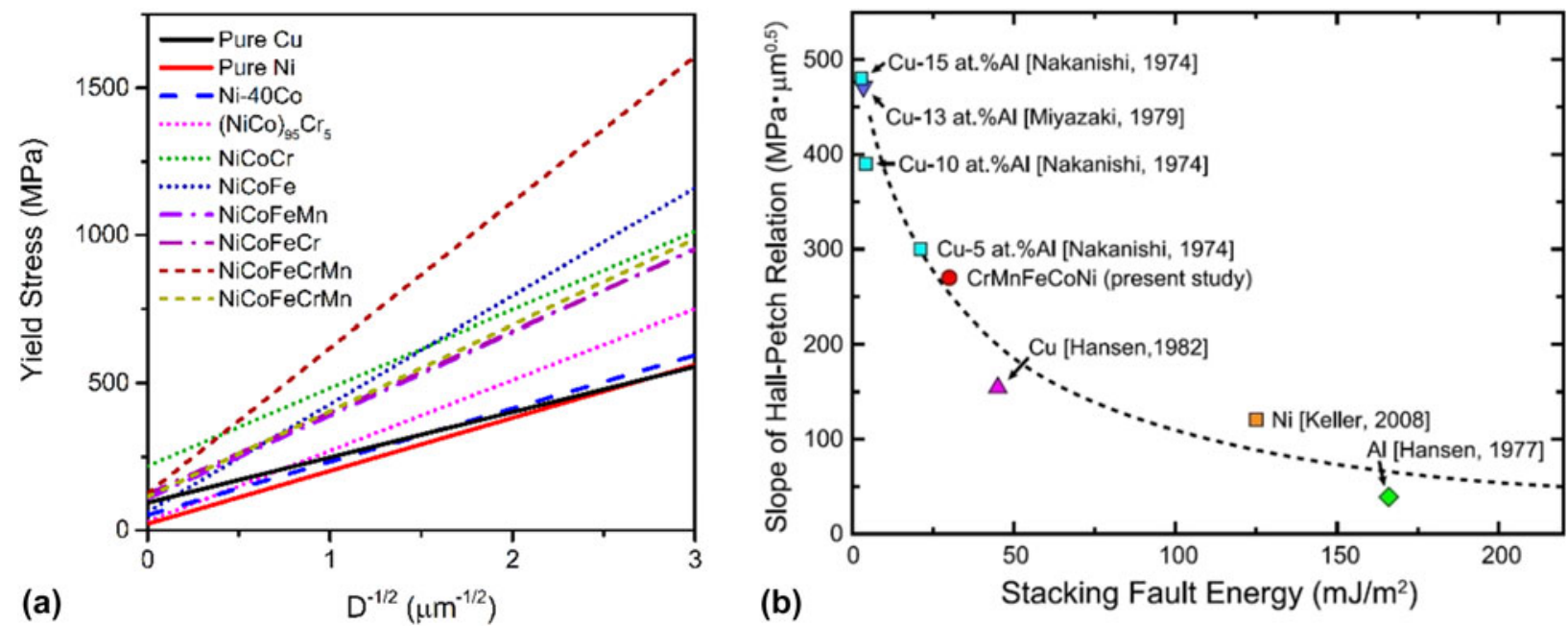

Figure 5: (a) Hall-Petch relationship for several low-, medium-, and high-entropy 3d transition metal alloys and (b) slope of Hall-Petch relationship versus SFE, adapted from Okamoto et al. [69]. Data from (a) were obtained from Refs. 69, 70, 71, 72, 73, and 74. 
Although $\mathrm{Al}$ in its pure form is a relatively soft material with low hardness $(\sim 107 \mathrm{HV})$, its addition to the CoCrFeNi system has resulted in remarkable hardening effects. This is caused by the formation of an Al-Ni rich BCC phase, which can form into wall-shaped ordered precipitates in alloys such as $\mathrm{Al}_{2} \mathrm{CoCrFeNi}$, producing a hardness of $500 \mathrm{HV}$ [76], which can be retained even at high temperatures $(200 \mathrm{HV}$ at $1273 \mathrm{~K}$; <50 $\mathrm{HV}$ for $\mathrm{CoCrFeNi)} \mathrm{[77].} \mathrm{Furthermore,} \mathrm{it} \mathrm{is} \mathrm{interesting} \mathrm{to} \mathrm{note}$ that the hardening effect caused by $\mathrm{Al}$ addition is more significant in the $\mathrm{CoCrFeNiCu}$ system than that in the CoCrFeNi system, which sees a broadened dual-phase (FCC + BCC) regime with a maximum hardness of $655 \mathrm{HV}$ [1]. As the $\mathrm{Al}$ content is increased, the $\mathrm{Al}_{x} \mathrm{CoCrCuFeNi}$ system shows a lower wear coefficient and higher resistance to anneal softening $[1,78]$. The excellent wear performance in this alloy is believed to be caused by a combined effect from SS hardening within the Al-rich BCC phase, precipitate hardening through the formation of nano-precipitates 3-50 nm in size, and nanocomposite strengthening resulting from nanoscale spinodal structures $(100-\mathrm{nm}$ wide dendrites with interspinodal plates $70 \mathrm{~nm}$ in width) [1].

The materials summarized thus far have all followed the expected inverse relation between hardness and wear coefficient, for example, the lowest observed wear coefficient of $1 \times$ $10^{-4} \mathrm{~mm}^{3} / \mathrm{Nm}$ is obtained at the composition in $\mathrm{Al}_{\mathrm{x}} \mathrm{CoCrCu}-$ FeNi which exhibits the highest hardness [78]. By contrast, in a system such as $\mathrm{Al}_{0.5} \mathrm{CoCrCuFeNiTi}$, the highest wear resistance of $1.3 \mathrm{~m} / \mathrm{mm}^{3}$ (with $x=1$ ) is not achieved at the highest hardness level (with $x=2$ ) [79]. This is a result of a loss of precipitate hardening because of the instability of the hard $\mathrm{CoCr}$ like phase with higher Ti content. Regardless, harder and finer

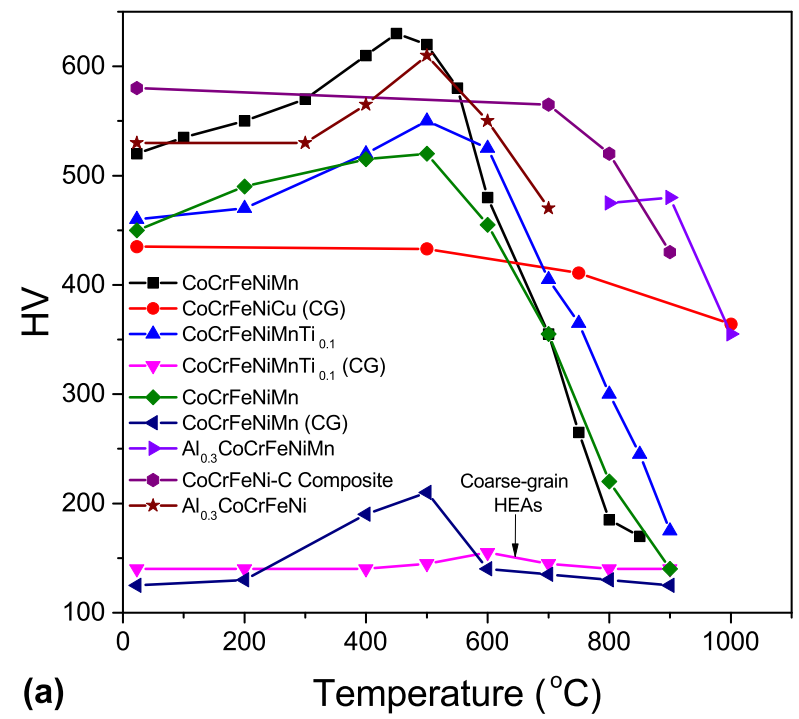

microstructures, controlled by both synthesis routes and alloy composition, typically improve the wear resistance of HEAs.

\section{Thermal stability of NC HEAs}

\section{Microstructure and mechanical stability}

The thermal stability of mechanical properties is one of the most popular topics in the field of NC HEAs, particularly for high-temperature applications. Figure 6 shows a few examples of the thermal stability of hardness and grain size of NC HEAs that have been mentioned in this article.

In reviewing Fig. 6, we can make direct comparisons of the stability of hardness between coarse- and nano-grained HEAs. Shahmir et al. [31, 46] have shown that in both CoCrFe$\mathrm{NiMnTi}_{2}$ and $\mathrm{CoCrFeNiMn}$, there is a considerable rise in the room temperature hardness (from $\sim 125 \mathrm{HV}$ to $\sim 450 \mathrm{HV}$ ) when the grain size is reduced from a few tens of micrometers down to sub-50 $\mathrm{nm}$ size. As temperature increases, we observe very good stability of these hardness values over an annealing time of one hour, up to a temperature of about $600{ }^{\circ} \mathrm{C}$. Likewise, with grain-size stability, we see that significant grain growth only begins at about $600{ }^{\circ} \mathrm{C}$. In general, most other alloys follow the same trend, although some HEAs exhibit pronouncedly more significant thermal stability, such as the CoCrFeNi-C composite, exceeding temperatures of $800{ }^{\circ} \mathrm{C}$ while maintaining $85 \%$ of its original strength after $600 \mathrm{~h}$ of annealing.

As shown in Fig. 6(b), we also observe that refractory-like HEAs, such as NbMoTaW, can operate and maintain smaller grain sizes at higher temperatures than purely $3 \mathrm{~d}$ transition metal HEAs. This is likely because those refractory elements,

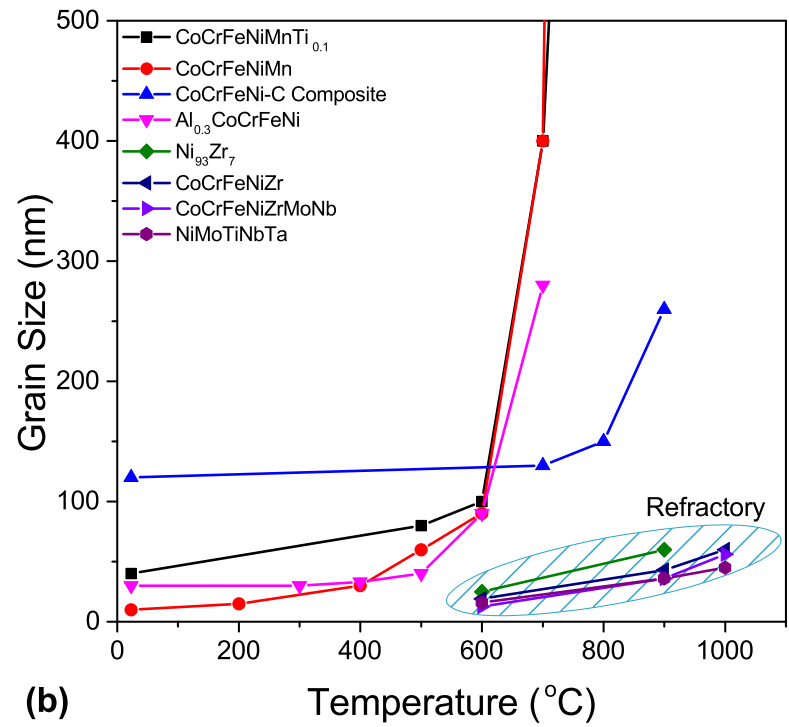

Figure 6: (a) Vicker's HV and (b) grain size of coarse-grain (CG) and NC HEAs as a function of annealing temperature. Annealing for all alloys was performed over one hour, except in the CG-CoCrFeNiCu and CoCrFeNi-C composites, which were annealed for five and $600 \mathrm{~h}$, respectively. The hatched region in (b) shows the refractory element-containing HEAs. Data were redrawn from Refs. 22, 28, 31, 46, 58, 59, 81, and 82. 


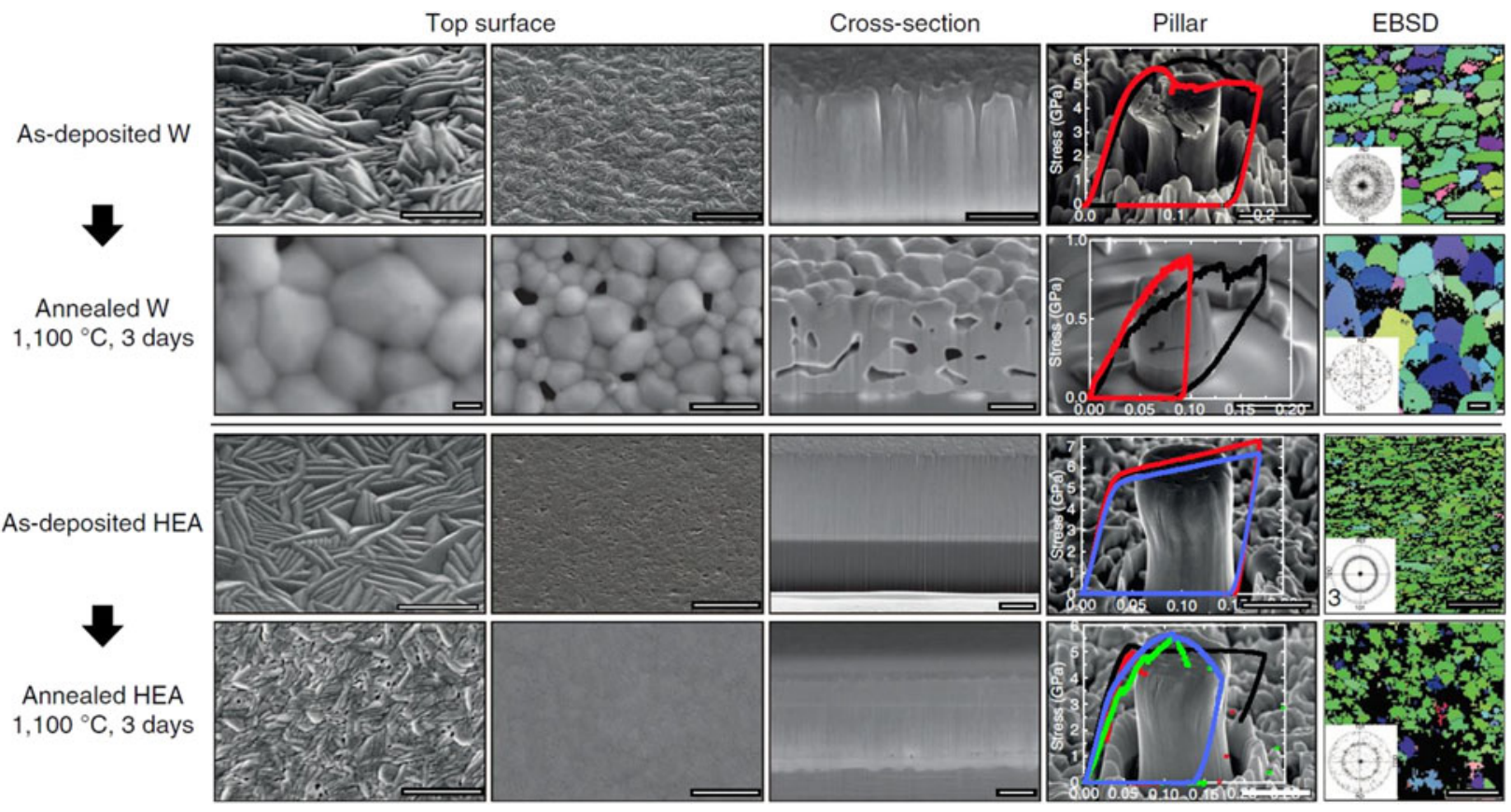

Figure 7: Pre- and postannealing structures of $\mathrm{W}$ and NbMoTaW HEA films after three days at $1100^{\circ} \mathrm{C}$. Scale bars, $200 \mathrm{~nm}$ (the first column, large magnification of top surfaces); $300 \mathrm{~nm}$ (the last column, EBSD maps); $1 \mu \mathrm{m}$ (other images). Reprinted from Ref. 19.

such as $\mathrm{Nb}, \mathrm{Mo}$, and $\mathrm{Ta}$, have higher melting points than the $3 \mathrm{~d}$ transition metal constituents, and as such may slow down the diffusion kinetics within the material. Zou et al. [19] demonstrated that the NbMoTaW system exhibits immense thermal stability as one of the refractory HEAs. Their work has shown that NC-NbMoTaW micropillars annealed at $1100{ }^{\circ} \mathrm{C}$ for $72 \mathrm{~h}$ experience no noticeable change in their initial grain size of 70$100 \mathrm{~nm}$ and yield strength of $\sim 5 \mathrm{GPa}$. These results are shown in Fig. 7.

In contrast to pure $\mathrm{W}$, which experiences a more than 10fold increase in grain size and a decrease in yield strength from $\sim 5 \mathrm{GPa}$ to less than $1 \mathrm{GPa}$, the performance of this HEA is staggeringly superior, suggesting that the theory behind thermal stabilization in HEAs does indeed have merit.

\section{Phase stability}

Another area of interest is the phase stability of these NC HEAs. A primary concern typically stems from the MAprocessed alloys, which require a combination of pressing and sintering after being refined to nanoscale grain sizes. Although long milling times have been shown to produce single-phase FCC and BCC structures, the consolidation process can have a negative impact of promoting phase decomposition.

In Fig. 8(a), Mohanty et al. [83] showed that the primary FCC phase in an AlCoCrFeNi alloy remains relatively stable up to SPS processing temperatures of $1173 \mathrm{~K}\left(900{ }^{\circ} \mathrm{C}\right)$. Kumar et al. [84] [Fig. 8(b)] showed the precipitation of a number of
IM phases from an initial mixed FCC + BCC AlCuCrFeMnW powder after SPS at $900{ }^{\circ} \mathrm{C}$. Transitioning to refractory-based HEAs [Figs. 8(c) and 8(d)], we see that in $\mathrm{Zr}_{70} \mathrm{Cu}_{24} \mathrm{Al}_{4} \mathrm{Nb}_{2}$ phase decomposition occurs at quite a low temperature [85], whereas in TiZrNbHfTa [42], there is a transition from singlephase to multiphase and back to single-phase through an annealing temperature range of $300-1100{ }^{\circ} \mathrm{C}$. From these results, it is clear that the phase decomposition behavior of HEAs is a process unique to each specific alloy composition, which is nearly impossible to accurately predict with the current state of modeling methods.

Although we typically want to take advantage of the SS hardening mechanisms in HEAs by promoting single-phase formation, decomposition of these alloys in multiple phases and/or precipitates can also have its advantages. A transition of the strengthening mechanisms can drastically alter an alloy's mechanical and functional properties, to the point where HEA design is a multivariable optimization problem.

\section{Functional properties of HEAs}

Compared with the vast number of studies on mechanical properties of NC HEAs, their functional properties, such as electrical, electrochemical, thermal, and magnetic properties, have been much less explored. This is due not only to an apparent negative trade-off between small grain sizes and many functional properties (e.g., corrosion resistance and electrical conductivity) but also to the extremely wide range in performances of many specific types of nanostructures. However, 

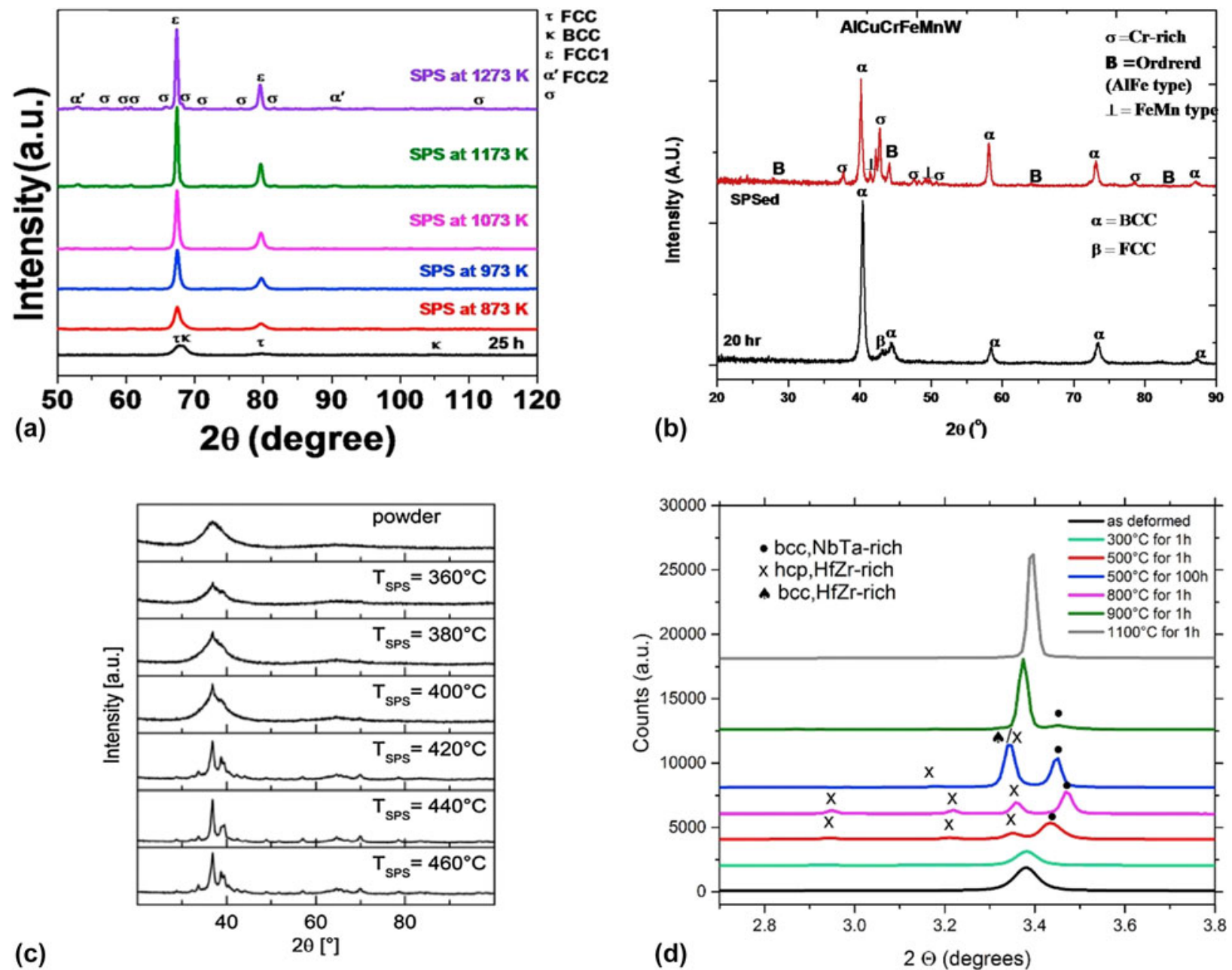

Figure 8: Thermal stability of the structure of NC HEAs processed via mechanical alloying and subsequent sintering: (a) AICoCrFeNi (reprinted with permission from Ref. 83, Copyright 2017 from Elsevier), (b) AlCuCrFeMnW (reprinted with permission from Ref. 84, Copyright 2018 from Elsevier), (c) $\mathrm{Zr}_{70} \mathrm{Cu}_{24} \mathrm{Al}_{4} \mathrm{Nb}_{2}$ (reprinted with permission from Ref. 85, Copyright 2018 from Elsevier), and (d) TiZrNbHfTa (reprinted with permission from Ref. 42, Copyright 2018 from Elsevier).

nanoscale structures in an HEA matrix, such as precipitates and secondary phases, indeed affect the functional performance significantly. Among all HEAs, most studies have focused on $\mathrm{Al}_{x} \mathrm{CoCrFeNi}[76,86,87,88,89,90,91]$. Such HEAs show considerable property variations that can be obtained through both a drive for phase transformation (from FCC to BCC) caused by different $\mathrm{Al}$ compositional ratios and nanostructure evolution resulting from its synthesis route. A summary of the functional properties of $\mathrm{Al}_{x} \mathrm{CoCrFeNi}$ HEAs is shown in Fig. 9. The effects on specific properties as they relate to different structures will be discussed in the following text.

\section{Corrosion resistance}

There is currently no unified theory for the effect of grain size on the corrosion behavior of HEAs, with opposing phenomena being observed for various material systems, grain-size ranges, and processing routes [92]. The formation of passive films is one of the key controlling factors of the corrosion resistance in materials. For example, corrosion resistance can be compromised because of unstable passive films in NC Ni [93], whereas $\mathrm{Ni}-\mathrm{Fe}$ alloys show similar corrosion resistance in both nanoscale and coarse-grained microstructures because of the formation of stable homogenous passive films [94]. There have been few studies on the comparison of corrosion performance between bulk and NC HEAs, but the investigation of specific nanostructures and their effect on corrosion are much more common.

In general, corrosion reactions will be significantly facilitated by a higher density of interfaces or grain boundaries where the activation energy of corrosion is lower. Thus, CoCrFeNi HEAs exhibit a lower corrosion resistance in its $\mathrm{NC}$ form (grain size $\sim 28 \mathrm{~nm}$ ) than its coarse-grained counterpart $[76,80]$. In addition, galvanic corrosion resulting from phase segregation is a major concern in HEAs due to the enhanced propensity of elements to segregate in these 


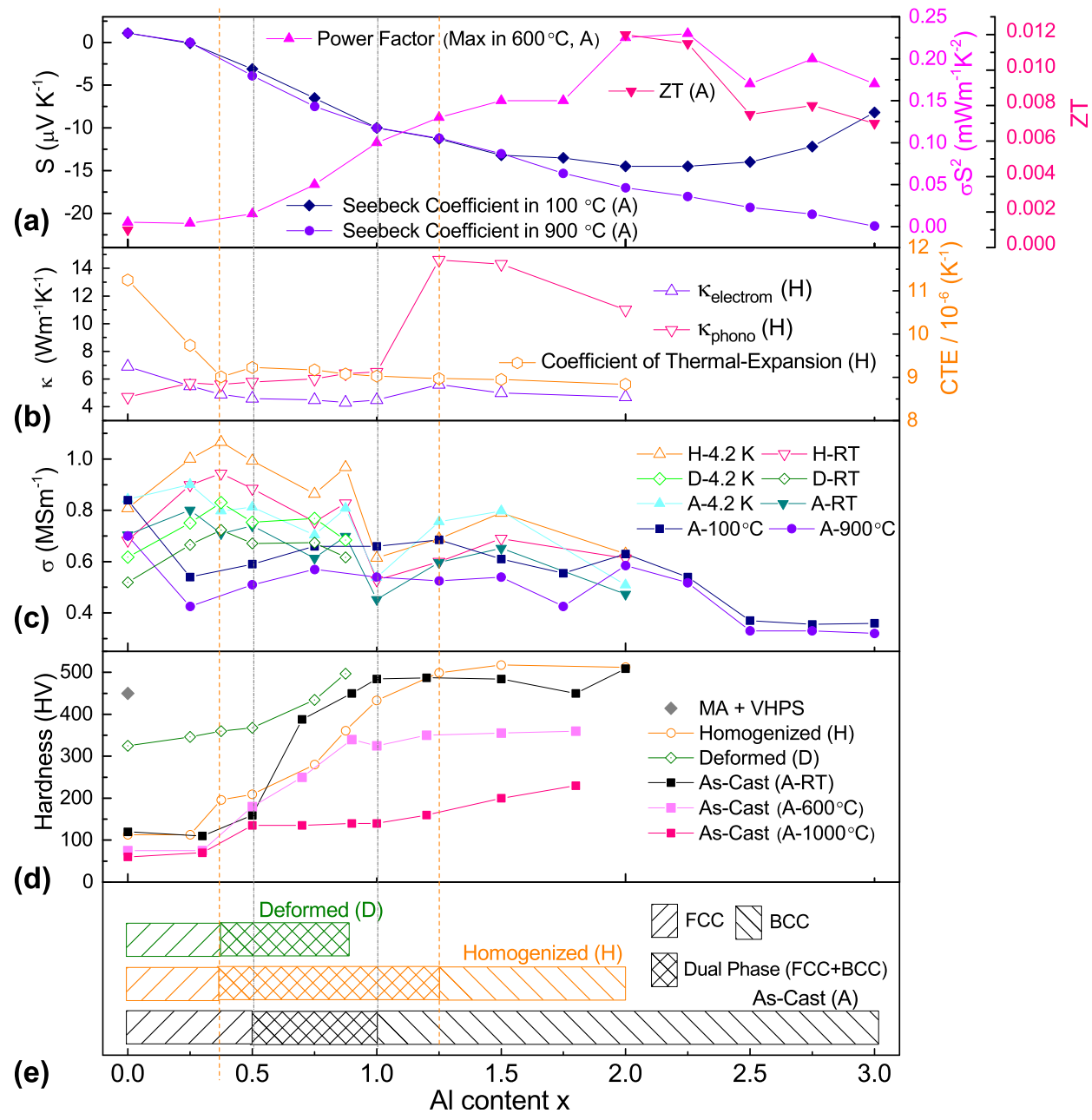

Figure 9: Functional properties of the $\mathrm{Al}_{x} \mathrm{CoCrFeNi}$ system as a function of Al-content $(x)$ : (a) Seebeck coefficient $(S)$, calculated power factors $\left(\sigma S^{2}\right)$, and figure-ofmerit (ZT); (b) thermal conductivity ( $\kappa$ ) and coefficient of thermal expansion (CTE); (c) electrical conductivity ( $\sigma$ ); (d) Vicker's hardness (HV); (e) phase boundary for as-cast, homogenized $\left(24 \mathrm{~h}\right.$ at $1100^{\circ} \mathrm{C}$ ) and deformed (rolling to $50 \%$ reduction in thickness) alloys. Data were collected from Refs. 5, 86, 87, 88, 89, 90 , and 91.

configurationally complex alloys. It has been demonstrated that $\mathrm{CoCrFeNiCu}$ with a grain size of $29 \mathrm{~nm}$ exhibits poorer corrosion resistance than $\mathrm{CoCrFeNi}$ with similar grain size, suggesting $\mathrm{Cu}$ is not an ideal candidate elemental addition in HEA systems for corrosion resistance [80, 95, 96]. Such an effect is also prevalent in Al-containing alloys, where significant segregation in $\mathrm{Al}_{x} \mathrm{CoCrFeNi}$ promotes the formation of $\mathrm{BCC}$ precipitates $50-100 \mathrm{~nm}$ in size within a uniform FCC matrix with increasing $\mathrm{Al}$ content, which in turn act as localized galvanic cells [90]. Compounding the effects of $\mathrm{Al}$ and $\mathrm{Cu}$ segregation, an increase in $\mathrm{Al}$ content in the $\mathrm{Al}_{x} \mathrm{CoCrCuFeNi}$ system has expectedly been shown to decrease its corrosion resistance [95].

Pit formation readily occurs in single-phase (FCC and BCC) HEAs, in which the BCC phase shows poorer corrosion resistance than the FCC phase; in dual-phase (FCC + BCC) systems, the interface structures are much more complex than systems with a single phase, and those complex phase boundaries with higher surface energy act as corrosion nucleation sites, therefore leading to localized corrosion [90]. Heat treatment is an effective approach to improve the corrosion resistance in these dual-phase HEAs, due to the homogenization effect in simplifying microstructures and compositions as well as reducing elemental segregations [88, 90, 96]. For example, BCC nanoparticles with 5- to 50-nm diameter transform to homogeneous FCC matrix in $\mathrm{Al}_{0.5} \mathrm{CoCrFeNi}$ after annealing, showing better corrosion resistance [90]. Meanwhile, samples with nanoscale dendrites $(\sim 50 \mathrm{~nm})$ prepared by direct laser fabrication exhibit a much poorer corrosion resistance than samples aged at $1200{ }^{\circ} \mathrm{C}$, which have a uniform FCC matrix [88]. Heat treatment could reduce the complexity of interfaces and boundaries and improve the homogeneity of elemental distribution in HEAs, resulting in low passivation/corrosion current and high 


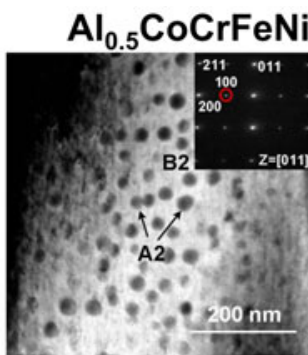

(a)

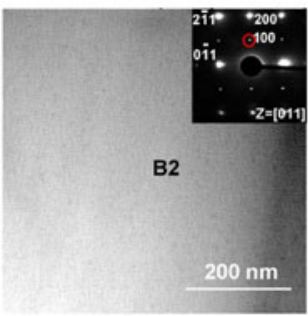

(e)

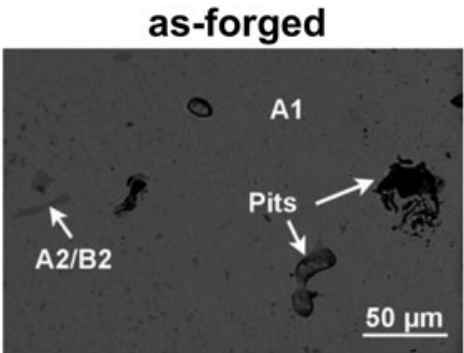

(b)

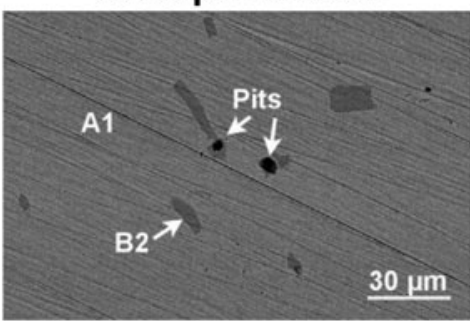

(f)

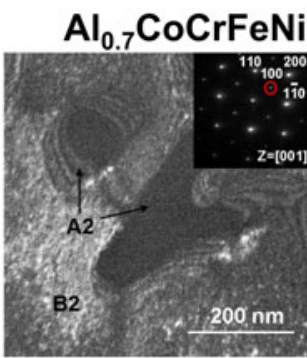

(c)

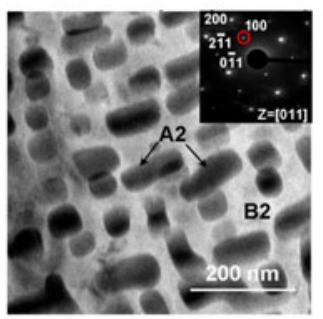

(g)

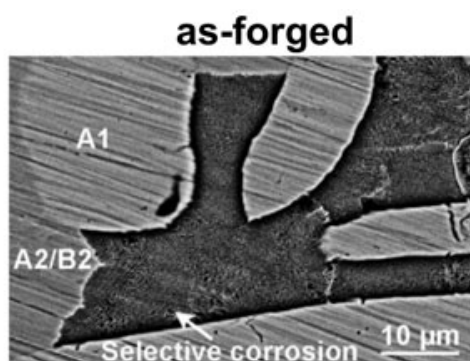

(d)

as-equilibrated

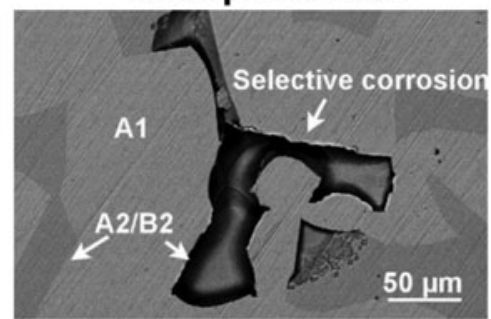

(h)

Figure 10: Characterization of nanostructures in HEAs by transmission electron microscopy (TEM) (a, c, e, g) and respective morphology of corrosion area after polarization by scanning electron microscopy $(\mathrm{SEM})(\mathrm{b}, \mathrm{d}, \mathrm{f}, \mathrm{h})$ in as-forged and as-equilibrated $\mathrm{Al}_{x} \mathrm{CoCrCuFeNi}$ samples with different $\mathrm{Al}$ content $(x=0.5$ and 0.7$)$. Reprinted with permission from Ref. 90. Copyright 2018 from Elsevier.

corrosion/pitting potential, therefore enhancing corrosion resistance. The influence of $\mathrm{Al}$ content and processing methods on morphology and nanostructures of $\mathrm{Al}_{x} \mathrm{CoCrCu}$ FeNi is shown in Fig. 10, along with corresponding corrosion performances.

As a common configurational element, $\mathrm{Cr}$ is a promising stable metallic addition for higher corrosion resistance in HEAs, especially for $\mathrm{AlCuFeNi}$, in which the grains of the dual-phase (FCC + BCC) alloy can be refined, resulting in a reduced corrosion rate [96]. The effect of $\mathrm{Ti}$, however, is much more controversial in different systems [96]. Noble elements dispersing into passive films can limit oxidation, and therefore improve corrosion resistance [95]. The effect of Mo on corrosion behavior is still under debate. Some studies have reported that Mo will facilitate elemental segregation [51], leading to more boundaries where severe localized corrosion will initiate. Others have shown Mo possesses the potential to protect the passive films and resist the penetration of $\mathrm{Cl}^{-}$ anions [95]. In contrast to the latter of these views, research on $\mathrm{TiZr}_{0.5} \mathrm{NbCr}_{0.5} \mathrm{~V}_{x} \mathrm{Mo}_{y}$ [97] has found a completely opposite result, in which general corrosion resistance in $\mathrm{NaCl}$ will deteriorate, whereas resistance in $\mathrm{H}_{2} \mathrm{SO}_{4}$ will be strengthened. Compared with Mo, $\mathrm{V}$ has been regarded as a better corrosionresistant additive element, showing enhanced corrosion resistance in both acid and chloride environments, with a low temperature sensitivity [97]. However, their nanoscale features have yet to be explored.

As far as current research is concerned, small grain sizes show a negative effect on corrosion resistance for HEAs. There is no clear relationship between configurational entropy and corrosion resistance, although intrinsic properties of elements and nanostructures such as phase segregation have a major influence on corrosion performance of HEAs. Regarding highentropy ceramics, such as $\mathrm{Al}_{0.5} \mathrm{CoCrCuFeNiB}_{x}$ [98] and $\mathrm{Cu}_{0.5} \mathrm{NiAlCoCrFeSi}$ [99], these examples exhibit either poor (B-containing) or excellent (Si-containing) corrosion resistance. This new class of HEMs will be discussed in section "High-entropy ceramics and oxides/nitrides".

\section{Electrical conductivity}

As a result of enhanced scattering of electrons due to grain refinement, the electrical conductivity is expected to be inherently low in NC materials. Electrons scattering in highentropy systems can be exacerbated because of high lattice distortion, which has been used to reduce electronic thermal conductivity in thermoelectric materials. As specific tests on electrical properties of HEAs are seldom conducted [91, 100, $101,102]$, electrical conductivity is often a property measured to characterize the thermoelectrical performance of materials $[86,87,89,103]$. The synthesis routes and compositions of NC HEAs can significantly affect their electrical properties. For example, in the $\mathrm{Al}_{x} \mathrm{CoCrFeNi}$ system [91], variations in electrical conductivity are observed in samples made by different fabrication methods (rather than the Al-content): homogenized samples with uniform nanostructure exhibit the lowest electrical resistivity, whereas high electrical resistivity can be obtained in plastically deformed samples because of the 
formation of a considerable density of defects. In the dualphase (FCC + BCC) AlCrCuFeMnTi system [100], despite significant differences in hardness, the electrical conductivity varies only slightly after relatively low-temperature annealing $\left(<995^{\circ} \mathrm{C}\right)$. With increasing annealing temperature to $1100{ }^{\circ} \mathrm{C}$, such HEAs show more distinct conductivity differences, which is attributed to the formation of a C14 phase $\left(\mathrm{MgZn}_{2}\right.$ hexagonal Laves structure) with subgrains about $500 \mathrm{~nm}$ in size, which impedes the movement of free electrons. Moreover, despite having the same carrier density, HEAs generally have lower carrier mobility than conventional alloys because of high lattice distortion.

It is interesting to find that a TaNbHfZrTi HEA system with a homogeneous $\mathrm{BCC}(\mathrm{TaNb})_{1-x}(\mathrm{ZrHfTi})_{x}$ nanostructure exhibits a combination of both crystalline- and amorphous-like features of transition metal superconductors. Such a phenomenon is mainly influenced by the mixing entropy of the system [101]. However, further exploration of the optimal composition of $(\mathrm{TaNb})_{0.67}(\mathrm{ZrHfTi})_{0.33}$ with $\mathrm{Al}$ additions has determined that $\mathrm{Al}$ is not an appropriate alloying element for developing superconductive HEAs [102].

\section{Thermal conductivity and thermoelectric properties}

As one of the proposed "core" effects in HEAs, severe lattice distortion can affect not only electron movement but can also drive phonon scattering and, therefore, reduce thermal conductivity [104]. Such an effect makes HEAs a promising class of potential high-performance thermoelectric materials, attracting significant research interest recently [103, 105]. In general, it has been recognized that the two most efficient ways of improving thermoelectric performance are (i) modifying a material's electronic/thermal transport properties and (ii) maintaining crystal symmetry for higher Seebeck coefficients. Both approaches can be applied by optimizing the entropy of the HEA systems [104].

In $\mathrm{Al}_{x} \mathrm{CoCrCuFeNi}$, both electrical conductivity and electronic thermal conductivity change slightly with increasing $\mathrm{Al}$ content. However, phono thermal conductivity is more sensitive to structure variation and shares much more influence on total thermal conductivity $\kappa$. Dual-phase samples possess the lowest value of $\kappa$ because of their complex nanostructures, such as nonuniformity of compositional elements and spinodal decompositions [86]. By increasing the symmetry and homogeneity of elemental distribution, an optimized combination of thermal conductivity and Seebeck coefficient can be obtained in this material made up of a single BCC phase $(x=2.0, Z T=$ $0.012)[86,87]$. Furthermore, a suitable annealing temperature can further improve the thermoelectric performance [90].
As the optimization of thermoelectric performance of HEAs requires a systematic approach rather than programmable high-throughput evaluation, similar nanostructures have been shown to exhibit completely opposing phenomena. For example, adding Gd to the CoCrFeNi system facilitates the formation of nanoscale Laves phases, leading to a decrease in all of its thermoelectric parameters (electrical conductivity, thermal conductivity, and Seebeck coefficient) and having a reduced figure of merit, $\mathrm{ZT}$ [89]. In the $\mathrm{NC}-\mathrm{Ti}_{2} \mathrm{NiCoSnSb}$ system (grain size $\sim 12 \mathrm{~nm}$ ), a secondary phase of $\mathrm{TiC}$ is obtained after long ball-milling times, facilitating more $\mathrm{Ni}_{3} \mathrm{Sn}_{4}$ formation and leading to higher electrical and thermal conductivities, but undermining the thermoelectric performance [103]. By contrast, Mn-rich nanoscale precipitates (20-30 $\mathrm{nm}$ in size) in SnTe-MnTe (medium-entropy) and $\mathrm{Sn}_{0.555} \mathrm{Ge}_{0.15} \mathrm{~Pb}_{0.075} \mathrm{Mn}_{0.275} \mathrm{Te}$ (high-entropy) systems promote the formation of nano line-defects, nanoscale strain clusters, and microscale interfaces, which scatter phonons and, therefore, reduce thermal conductivity, leading to excellent thermoelectric properties [106, 107]. The results from these studies showing the synergetic effect between nanostructure and lattice distortion are shown in Fig. 11. Moreover, many other additive elements such as $\mathrm{Zr}, \mathrm{Ti}, \mathrm{V}, \mathrm{Mo}$, and $\mathrm{Hf}$ in $\mathrm{NbFeSb}$ [105] reinforce the severe lattice-distortion effect. This serves to strongly scatter phonons, resulting in low lattice thermal conductivity and enhanced Seebeck coefficient, leading to excellent thermoelectric properties. Hence, despite that high lattice distortion shows a positive effect on thermoelectrical properties in high-entropy systems, there seems to be no obvious relation toward the influence of nanostructures.

\section{Magnetic properties}

Elemental composition is the major controlling factor of the magnetic properties of HEAs. $\mathrm{Fe}, \mathrm{Co}$, and $\mathrm{Ni}$ are identified as ferromagnetic elements, and $\mathrm{Cr}$ is recognized as an antiferromagnetic element, resulting in a reduced ferromagnetic property for the CoCrFeNi system [80]. As a diamagnetic material, $\mathrm{Cu}$ significantly reduces the magnetization of a system and causes soft magnetic properties [80]. The FCC and BCC phases in $\mathrm{Al}_{x} \mathrm{CoCrFeNi}$ alloys show opposing magnetism characteristics, and as such a decrease in magnetization and magnetism transition (from ferromagnetic to paramagnetic) is observed with increasing temperature [91]. Interestingly, the magnetic properties in this alloy appear to be unaffected by increasing Al-content [91].

So far, there have been few relevant studies on the magnetic properties of NC HEAs. For example, magnetic properties of a BiFeCoNiMn HEA system [108] depend on their nanostructures: with decreasing molar ratio of $\mathrm{Bi}(\mathrm{III})$ to divalent 

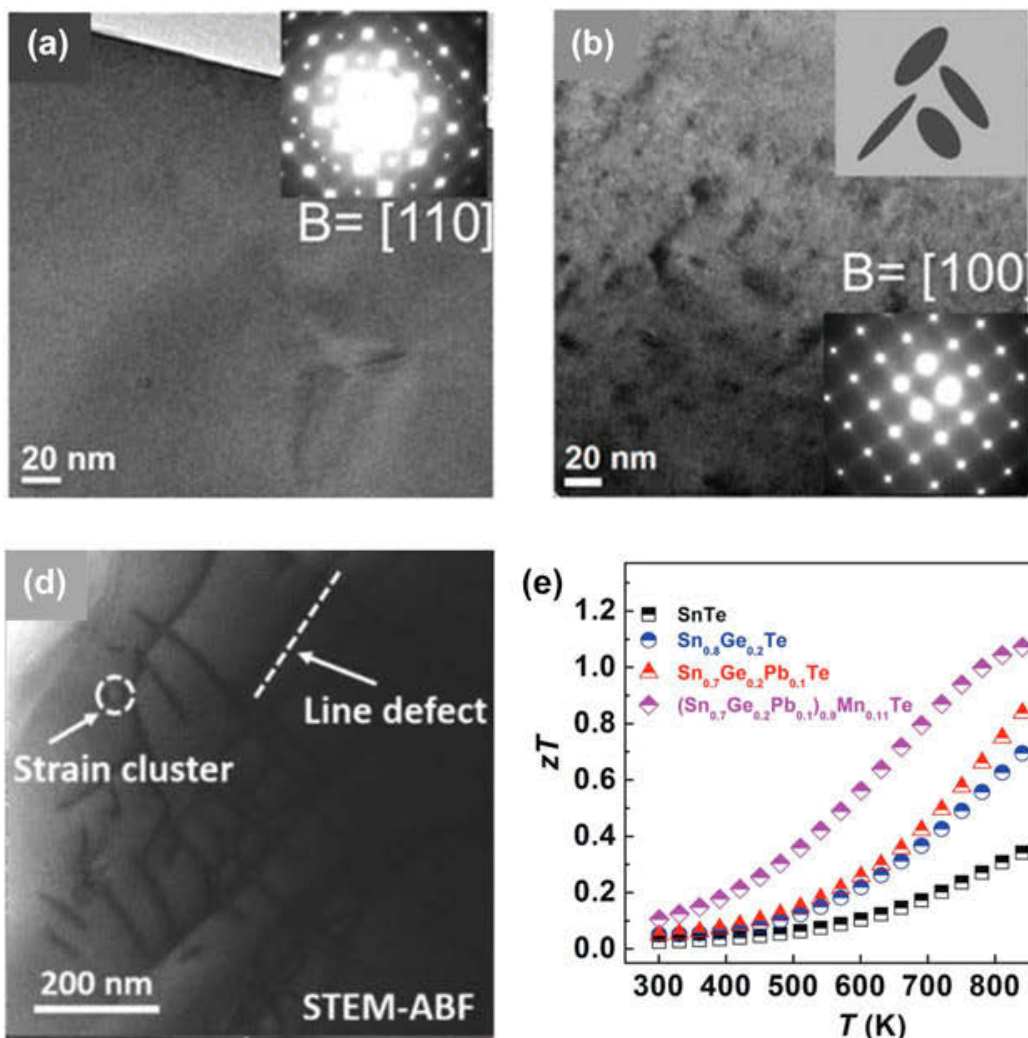

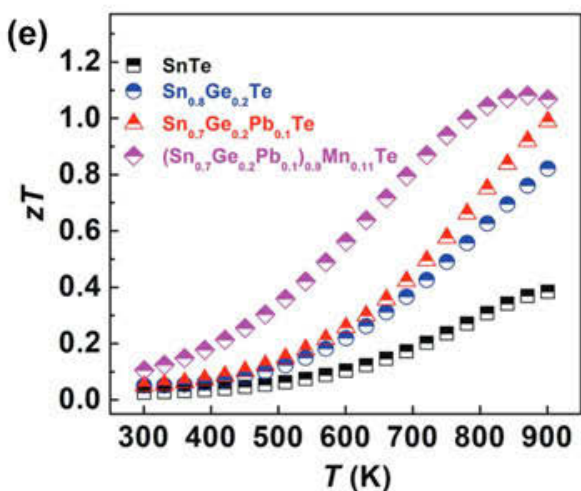

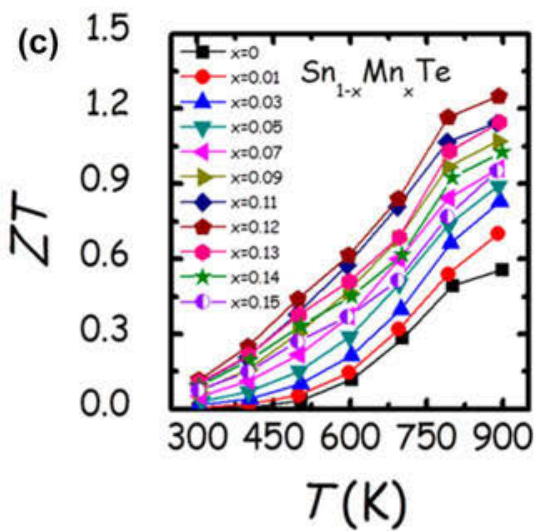

(f)

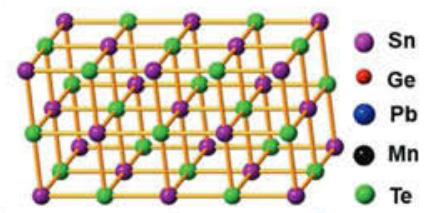

(g)

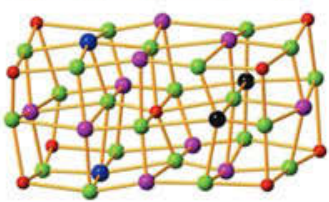

Figure 11: (a) TEM image of $\mathrm{Sn}_{0.93} \mathrm{Mn}_{0.07} \mathrm{Te}$ without precipitates; (b) TEM image of $\mathrm{Sn}_{0.88} \mathrm{Mn}_{0.12} \mathrm{Te}$, showing orthogonal nanoprecipitates; (c) thermoelectrical properties of $\mathrm{Sn}_{1-x} \mathrm{Mn}_{x} \mathrm{Te}$ samples, in which $\mathrm{Sn}_{0.88} \mathrm{Mn}_{0.12} \mathrm{Te}$ presents the highest temperature-dependent $\mathrm{ZT}$ values; (d) high density of line defects in $\left(\mathrm{Sn}_{0.7} \mathrm{Ge}_{0.2} \mathrm{~Pb}_{0.1}\right)_{0.9} \mathrm{Mn}_{1.1} \mathrm{Te}$ viewed by STEM; (e) corresponding ZT values in comparison with other lower order systems; $(\mathrm{f})$ and $(\mathrm{g})$ schemes of the lattice structures of pure SnTe and $\left(\mathrm{Sn}_{0.7} \mathrm{Ge}_{0.2} \mathrm{~Pb}_{0.1}\right)_{0.9} \mathrm{Mn}_{1.1} \mathrm{Te}$ system, respectively. (a)-(c) reprinted (adapted) with permission from Ref. 106. Copyright 2015 from American Chemical Society. (d)-(g) reprinted with permission from Ref. 107. Copyright 2018 from John Wiley and Sons.

transition metal ions ( $\mathrm{Fe}, \mathrm{Co}, \mathrm{Ni}$, and $\mathrm{Mn}$ ) their amorphous structure transitions into nanorods $(50-70 \mathrm{~nm}$ in length and $10 \mathrm{~nm}$ in diameter) through a "grain-to-rod" transformation. Such transformation leads to a decrease in exchange coupling that results from a larger distance than the exchange-correlation length, along with which the soft magnetic and paramagnetic materials change into one with hard magnetic anisotropy, that is, magnetic hardening. One must also consider that nearly all magnetocaloric alloys with magnetocaloric effect are metallic glasses, showing amorphous rather than NC structures [109]. Despite the concept of "high-entropy bulk metallic glasses” proposed recently [110], these noncrystalline structures are not classified within the conventional definition of HEAs.

\section{Hydrogen storage}

The hydrogen storage properties of HEAs have attracted significant research interests recently $[111,112]$. In conventional research on hydrogen storage material, compositional selection is usually focused on transition metals such as $\mathrm{Ti}, \mathrm{V}, \mathrm{Ni}$, and $\mathrm{Zr}$, which are similar to compositions of HEMs [113]. Many HEA systems possess the potential for hydrogen absorption. However, elements with high atomic weight (high Z-number) in certain high-entropy systems reduce the hydrogen capacity below the requirement for practical applications of hydrogen storage. For example, the mass capacity of TiZrNbMoV is in the range of 2.3$2.5 \mathrm{wt} \%$ [111]. Hence, most HEAs are not seen as promising hydrogen storage candidates. Another use of hydrogen atoms within metal lattices is for use as an indicator to present the difference of structure between HEAs and traditional alloys [112]. The presence of hydrogen in metallic systems also has an effect on mechanical properties, which is another important research direction to be conducted in the field of HEAs [114, 115].

\section{Nanostructured high-entropy materials}

Beyond NC HEAs, studies on nanotwins, nanoprecipitates, and nanoscale segregation in HEAs have also been conducted. Such structures can have considerable effects on strength, corrosion initiation, and other functional properties. As discussed in section "Materials for NC HEAs", several different processing routes, ranging from cryogenic to high-temperature scales, can be used to obtain these structures. For example, deformationinduced nanotwinning is the principal mechanism for 
cryogenic fracture resistance. The addition of nonmetallic elements into multielement systems can also provide unique properties in mechanical and functional applications, especially in reversible energy storage, broadening the research class of HEMs. Thus, this section is mainly focused on specific nanostructures of HEAs as well as high-entropy ceramics/oxides. The phases, structure characteristics, and properties of these HEMs are summarized in Table II.

\section{Nanotwinning and phase transformations}

Conventionally, metallic materials at low temperatures tend to exhibit increased strength and decreased fracture resistance. The CrMnFeCoNi alloy breaks such trade-off by introducing nanoscale twinning during plastic deformation [116, 117]. Deformation-induced nanotwinned structures and planar slip are discerned as the mechanisms for their excellent cryogenic behavior (1280 $\mathrm{MPa}$ strength with $>0.7$ ductility) during steady-strain hardening rather than necking from plastic instability, in contrast to grain disorientation due to dislocation activity being the reason for ambient temperature deformation (759 MPa with $\sim 0.5$ ductility) [116]. This nanotwin-mediated plasticity has been further improved with the addition of 0.5 at.\% C [117], showing a higher strength with good ductility at low temperature, however, compromising the performance at ambient temperature. It is recognized that the formation of deformation-induced nanoscale twinning is attributed to dissociation within the glide of dislocations, driven from their precursors as stacking faults [118]. Local atomic environments and thermodynamic stabilities of stacking sequences influence the SFE of materials [119], and a lower SFE caused by elemental addition will, in turn, facilitate the formation of stacking faults and hence nanotwinning [117]. Of practical interest is the amount and type of elemental additions to be implemented into an alloy, since an imbalance of certain elements might compromise the ductility despite the formation of nanoscale twinning (e.g., $\mathrm{SiC}$ nanoparticles in the $\mathrm{CoCr}$ FeMnNi system [44]). Moreover, a similar result has also been found in the $\mathrm{Fe}_{80-x} \mathrm{Mn}_{x} \mathrm{Co}_{10} \mathrm{Cr}_{10}$ system [120], in which the strength-ductility trade-off could be overcome by a dynamic strain-stress partitioning effect [121] because of good plasticity caused by phase transformation and twinning formation. However, although nanotwinned structures could significantly improve the mechanical properties of HEAs, they are deformation-induced structures rather than intrinsic ones. Thus, future studies focusing on the fabrication of HEAs with intrinsic nanoscale twinning could be a promising research direction.

Phase transformations in HEAs can result from the addition of various elements such as $\mathrm{Al}[77,86]$ and $\mathrm{Ti}$ [79] or can be affected by synthesis routes $[76,77,88]$. For example, with increased $\mathrm{Al}$ content, the $\mathrm{FCC}$ phase of $\mathrm{CoCrFeNi}$ transitions into a BCC phase, and the dual-phase region is broadened after homogenization in which dendrite and interdendritic segregation with spinodal structure could be obtained $[76,86,90]$. During use, the occurrence of phase transformations depends on the stability of each phase under particular operating conditions. Contrary to conventional belief, the $\mathrm{CoCrFeNi}$ system exhibits metastability in the dominant phase at intermediate temperatures, showing obvious elemental decomposition [122]. The rate of phase segregation could be accelerated by adding specific segregation-inducing elements such as $\mathrm{Al}, \mathrm{Cu}$, and $\mathrm{B}[96,122]$.

Regarding irradiation damage, high stability can be obtained in HEAs as a result of the high atomic-level stresses in multicomponent alloys, providing a damage healing mechanism [123]. Zr-Hf-Nb alloys possess excellent irradiation resistance and show no electron irradiation-induced structural changes [124]. In $\mathrm{CoCuCrFeNi}$, although phase segregation can occur after sintering of MA powders [80], homogeneous structures can be obtained in samples synthesized by co-sputter deposition, showing good stability under high-voltage electron irradiation [34]. Radiation in HEAs can also be used to characterize the sluggish diffusion in HEAs [125].

\section{High-entropy ceramics and oxides/nitrides}

Some multielement materials with high proportions of nonmetallic elements, for example, Si [99, 126], present excellent properties. For example, FeCoNi(AlSi) $)_{0.2}$, with an FCC structure, possesses good mechanical properties (342 MPa yield strength with $50 \%$ ductility), as well as promising soft magnetic properties (1.15 $\mathrm{T}$ saturation magnetization, $1400 \mathrm{~A} / \mathrm{m}$ coercivity, and $69.5 \mu \Omega \mathrm{cm}$ electrical resistivities) [126]. However, with increasing Si content, a BCC phase transition occurs, after which a brittle fracture mechanism takes over. Moreover, nitrided HEA films have also been widely investigated and offer themselves as a promising class of engineering surface materials [35, 127], showing an FCC structure (NaCl-type) with homogeneous elemental distribution and exhibiting high hardness and thermal stability. NC-AlCrTaTiZr-nitride films have also been recognized as an excellent diffusion barrier in $\mathrm{Cu}$ metallization [128].

The concept of high-entropy ceramics was not widely accepted until a few studies on entropy-stabilized oxides [129] and nitrides [35] were reported. Such materials have more recently been recognized as forms of HEMs. Hightemperature processing is generally beneficial toward the formation of entropy-stabilized oxides and nitrides. With increasing temperature, the structure of $(\mathrm{MgNiCoCuZn}) \mathrm{O}$ system changes from a mixture of original phases of $\mathrm{MgO}$, $\mathrm{NiO}, \mathrm{ZnO}, \mathrm{CuO}$, and $\mathrm{CoO}$ to a homogenous single-phase rock 
TABLE II: Phases, nanostructures, properties and synthesis methods of HEMs.

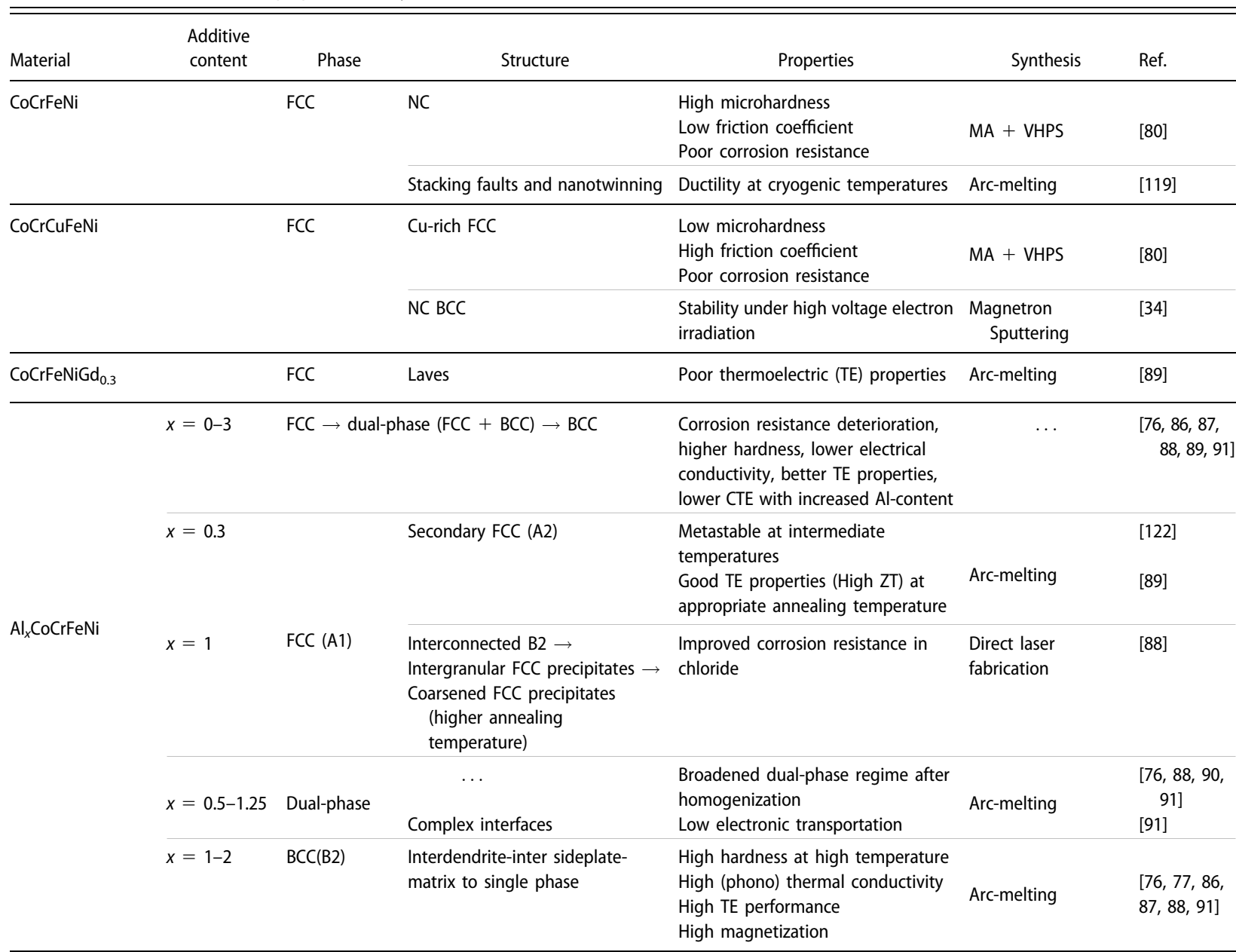

\begin{tabular}{|c|c|c|c|c|c|c|}
\hline \multirow{3}{*}{$\mathrm{Al}_{x} \mathrm{CoCrCuFeNi}$} & $x=0-3$ & $\mathrm{FCC} \rightarrow$ dual & lase $(\mathrm{FCC}+\mathrm{BCC}) \rightarrow \mathrm{BCC}$ & Higher hardness and lower wear & \multirow{3}{*}{ Arc-melting } & [78] \\
\hline & $\begin{array}{l}x=0-0.6 \\
x=0.6-2.6\end{array}$ & $\begin{array}{l}\text { FCC } \\
\text { Dual-phase }\end{array}$ & $\begin{array}{l}\text { Nancoprecipitate }+ \text { nano-spaced } \\
\text { spinodal structure }\end{array}$ & NC dispersion SS strengthening & & \multirow[t]{2}{*}[75]{} \\
\hline & $x=2.6-3$ & $\mathrm{BCC}$ & Nano-spaced spinodal structure & Nanocomposite strengthening & & \\
\hline \multicolumn{2}{|l|}{ AlCoCuFeNi-Cr } & $\mathrm{FCC}+\mathrm{BCC}$ & Cu-rich FCC + laves & $\begin{array}{l}\text { Higher strength and improved } \\
\text { corrosion resistance with } \mathrm{Cr} \text { addition } \\
\text { Higher strength but lower corrosion } \\
\text { resistance with } \mathrm{Ti} \text { addition }\end{array}$ & Arc-melting & {$[150]$} \\
\hline $\mathrm{Al}_{0.5} \mathrm{CoCrCuFeNiTi}{ }_{x}$ & $\begin{array}{l}x=0-0.4 \\
x=0.4-0.8 \\
x=0.8-1.2 \\
x=1.2-2.0\end{array}$ & $\mathrm{FCC}+\mathrm{BCC}$ & $\begin{array}{l}\mathrm{CoCr} \text {-like and } \mathrm{Ti}_{2} \mathrm{Ni} \text {-like nano- } \\
\text { precipitates } \\
\mathrm{Ti}_{2} \mathrm{Ni} \text {-like nano-precipitates }\end{array}$ & $\begin{array}{l}\text { High hardness } \\
\text { Highest wear coefficient (best wear } \\
\text { resistance) } \\
\text { Highest hardness }\end{array}$ & Arc-melting & [79] \\
\hline $\mathrm{Co}_{10} \mathrm{Cr}_{10} \mathrm{Fe}_{80-x} \mathrm{Mn}_{x}$ & $\begin{array}{l}x=0.45 \\
x=0.35 \\
x=0.30\end{array}$ & $\mathrm{FCC}+\mathrm{HCP}$ & $\begin{array}{l}\text { Deformation-induced } \\
\text { nanotwinning }\end{array}$ & $\begin{array}{l}360 \mathrm{MPa} \text { tensile strength with } 45 \% \\
\text { ductility } \\
700 \mathrm{MPa} \text { tensile strength with } 50 \% \\
\text { ductility } \\
900 \mathrm{MPa} \text { tensile strength with } 75 \% \\
\text { ductility }\end{array}$ & $\begin{array}{l}\text { Vacuum induction } \\
\text { casting }+ \text { rolling }\end{array}$ & {$[120$} \\
\hline \multirow[t]{2}{*}{ CoCrFeMnNi } & $\begin{array}{l}0.5 \text { at. } \% \\
\text { carbon }\end{array}$ & FCC & $\begin{array}{l}\text { Deformation-induced } \\
\text { nanotwinning }\end{array}$ & $\begin{array}{l}\text { Remarkable cryogenic fracture } \\
\text { resistance } \\
\text { Promising cryogenic strength and } \\
\text { ductility }\end{array}$ & Arc-melting & [116] \\
\hline & $\begin{array}{l}5 \mathrm{wt} \% \mathrm{SiC} \\
\text { nanoparticles }\end{array}$ & & & Poor strength and plasticity & $\begin{array}{l}\text { MA }+ \text { Hot isostatic } \\
\text { pressing }\end{array}$ & [44] \\
\hline
\end{tabular}


TABLE II: Phases, nanostructures, properties and synthesis methods of HEMs. (continued)

\begin{tabular}{|c|c|c|c|c|c|c|}
\hline $\begin{array}{l}\text { TaNbHfZrTi } \\
\text { TaNbHfZrTiAl }\end{array}$ & & $\mathrm{BCC}$ & $\beta$-uranium structure & $\begin{array}{l}\text { Promising superconductivity } \\
\text { Poor superconductivity }\end{array}$ & Arc-melting & $\begin{array}{l}{[101]} \\
{[102]}\end{array}$ \\
\hline $\mathrm{Bi}_{x}(\mathrm{CoFeMnNi})$ & $\begin{array}{c}x=0.16- \\
0.48\end{array}$ & $\begin{array}{l}\mathrm{FCC} \rightarrow \\
\quad \text { amorphous }\end{array}$ & $\begin{array}{l}\text { Nano-grain to nanorod } \\
\text { transformation }\end{array}$ & $\begin{array}{l}\text { FCC phase: Excellent magnetic } \\
\text { properties }\end{array}$ & Electrodeposition & [108] \\
\hline $\begin{array}{l}\left(\mathrm{Sn}_{0.7} \mathrm{Ge}_{0.2} \mathrm{~Pb}_{0.1}\right)_{1-x} \\
\mathrm{Mn}_{1.1 x} \mathrm{Te}\end{array}$ & $x=0.1-0.3$ & FCC & $\begin{array}{l}\text { Mn-rich nano-precipitates } \\
\text { Atomic-scale point and line } \\
\text { defects, nanoscale strain clusters, } \\
\text { and microscale interfaces }\end{array}$ & $\begin{array}{l}\text { Low lattice thermal conductivity } \\
\text { Highest seebeck coefficient of } \sim 230 \\
\mu \mathrm{V} / \mathrm{K} \text { at } 900 \mathrm{~K} \\
\text { Low thermal conductivity and better } \\
\mathrm{TE} \text { properties. } \\
\text { For } x=0.25, \mathrm{ZT}=1.42 \text { at } 900 \mathrm{~K}\end{array}$ & Melting & [107] \\
\hline $\begin{array}{l}\mathrm{Nb}_{1-x} \mathrm{FeSb} \\
\left(\mathrm{ZrTiVMoHf}_{x}\right.\end{array}$ & $x=0-0.4$ & \multicolumn{2}{|c|}{ Half-Heusler (FCC) } & $\begin{array}{l}\text { Promising TE properties } \\
\text { Lower lattice thermal conductivity } \\
\text { with increasing } x\end{array}$ & Arc-melting + SPS & [105] \\
\hline $\mathrm{Ti}_{2} \mathrm{NiCoSnSb}$ & & $\begin{array}{l}\text { Half-Heusler } \\
\qquad(F \overline{4} 3 m) \\
\ldots\end{array}$ & $\begin{array}{l}\text { Microcrystalline } \\
\mathrm{NC}+\mathrm{Ni}_{3} \mathrm{Sn}_{4} \text { and } \mathrm{TiC} \\
\text { precipitates }\end{array}$ & $\begin{array}{l}\text { Promising TE properties after short- } \\
\text { term ball-milling } \\
\text { High thermal and electrical } \\
\text { conductivity, poor TE properties } \\
\text { after long-term ball-milling }\end{array}$ & $B M+S P S$ & [103] \\
\hline $\mathrm{TiZr}_{0.5} \mathrm{NbCr}_{0.5}$ & & & $\ldots$ & $\begin{array}{l}\text { No obvious corrosion regions } \\
\text { Poor general corrosion resistance } \\
\text { Good pitting corrosion resistance in }\end{array}$ & & \\
\hline & & $\mathrm{BCC}$ & Ordered $\mathrm{Cr}_{2} \mathrm{Zr}$ phase & $\begin{array}{l}\text { Good corrosion resistance in } \mathrm{H}_{2} \mathrm{SO}_{4} \\
\text { solution } \\
\text { Localized corrosion on boundaries }\end{array}$ & Arc-melting & [97] \\
\hline $\mathrm{TiZr}_{0.5} \mathrm{NbCr}_{0.5} \mathrm{~V}$ & & & & $\begin{array}{l}\text { Low temperature sensitivity of } \\
\text { corrosion rate }\end{array}$ & & \\
\hline
\end{tabular}

$\begin{array}{ll}\mathrm{Cu}_{0.5} \mathrm{AlCoCrFeNiSi} \quad \mathrm{BCC} & \text { Nanoscale precipitates at } \\ & \text { amorphous interdendritic phases }\end{array}$

High hardness (860 HV)

Resistant to general corrosion

Less resistant to pitting corrosion Arc-melting

[99]

Poor corrosion resistance in acids

containing chloride ions

$342 \mathrm{MPa}$ yield strength with $50 \%$

ductility

CoFeNi(AISi) $0.2 \quad$ FCC

High saturation magnetization (1.15 T), Arc-melting

coercivity $(1400 \mathrm{~A} / \mathrm{m})$ and electrical

resistivity $(69.5 \mu \Omega \mathrm{cm})$

\begin{tabular}{llll}
\hline AlCrTaTiZr-nitride & FCC & NC & $\begin{array}{l}\text { Excellent diffusion barrier in Cu } \\
\text { metallization }\end{array}$ \\
\hline
\end{tabular}

High-entropy oxides

Colossal dielectric constant $(2 \times \quad$ Milling + hot

$10^{5}$ ) at $440 \mathrm{~K}$ with high bulk isostatic pressing

resistance $(30 \mathrm{M} \Omega)$

$(\mathrm{Mg}, \mathrm{Ni}, \mathrm{Co}, \mathrm{Cu}, \mathrm{Zn}) \mathrm{O} \quad$ Rock salt (NaCl-type FCC)

Lithium ion conductivities with high Nebulized Spray

capacity for lithium battery

pyrolysis

Cation-doped: Good catalytic Co-precipitation

activity of $\mathrm{CO}$ oxidation

$\left(\mathrm{Hf}_{0.25} \mathrm{Zr}_{0.25} \mathrm{Ce}_{0.25}\right) \quad \mathrm{M}=\mathrm{Yb}, \mathrm{Ca}$, Fluorite High hardness

$\left(\mathrm{Y}_{0.25} \mathrm{M}_{\mathrm{X}}\right) \mathrm{O}_{2-\delta} \quad \mathrm{Gd}$, La etc. Fluorite Low thermal and

conductivities

\begin{tabular}{rlll}
\hline & $\mathrm{A}=\mathrm{Sr}, \mathrm{Ba}$ & & \\
$\left(5 \mathrm{~A}_{0.2}\right)\left(5 \mathrm{~B}_{0.2}\right) \mathrm{O}_{3}$ & $\mathrm{~B}=\mathrm{Zr}, \mathrm{sn}, \mathrm{Ti}$, Perovskite & $\begin{array}{l}\text { Secondary phase for } \\
\text { sfome compositions }\end{array}$ & Antiferromagnetic behaviors
\end{tabular}

$\mathrm{Hf}, \mathrm{Nb}$

Layered hexagonal $(P 6 / \mathrm{mmm})$

$M A+S P S$

[140]

\begin{tabular}{llll}
\hline High-entropy diborides $\quad$ Layered hexagonal $(P 6 / \mathrm{mmm})$ & {$[140] \quad$ MA + SPS } \\
\hline
\end{tabular}


TABLE II: Phases, nanostructures, properties and synthesis methods of HEMs. (continued)

\begin{tabular}{|c|c|c|c|c|c|}
\hline High-entropy carbides & Rock Salt & & $\ldots$ & $\mathrm{MA}+\mathrm{SPS}$ & [141] \\
\hline \multicolumn{5}{|l|}{ High-entropy silicides } & [142] \\
\hline \multicolumn{6}{|l|}{ High-entropy sulfides } \\
\hline $\begin{array}{l}\mathrm{Cu}_{5} \mathrm{SnMgGeZnS}_{9} \\
\mathrm{Cu}_{3} \mathrm{SnMg} \operatorname{lnZnS} \mathrm{S}_{7}\end{array}$ & Tetragonal & $\begin{array}{l}\text { Metallic } \\
\text { Semiconducting }\end{array}$ & $\begin{array}{l}\text { Low lattice } \\
\text { thermal } \\
\text { conductivity }\end{array}$ & $\mathrm{MA}+\mathrm{SPS}$ & [143] \\
\hline \multicolumn{6}{|c|}{ High-entropy intermetallic compounds (HEICs) } \\
\hline $\begin{array}{l}\left(\mathrm{Co}_{0.25} \mathrm{Fe}_{0.25} \mathrm{Ni}_{0.25} \mathrm{Mn}_{0.25}\right) \mathrm{Al} \\
\left(\mathrm{Co}_{0.25} \mathrm{Fe}_{0.25} \mathrm{Ni}_{0.25} \mathrm{Cu}_{0.25}\right) \mathrm{Al} \\
\left(\mathrm{Fe}_{0.2} \mathrm{Co}_{0.2} \mathrm{Ni}_{0.2} \mathrm{Mn}_{0.2} \mathrm{Cu}_{0.2}\right) \mathrm{Al}\end{array}$ & B2 phase & $\begin{array}{l}\text { Bridging the con } \\
\text { HEAs and nonm } \\
\text { ceramics }\end{array}$ & $\begin{array}{l}\text { ventional metallic } \\
\text { etallic high-entropy }\end{array}$ & $M A+S P S$ & [145] \\
\hline
\end{tabular}

salt structure [129]. Comparing the (CoCuMgNiZn)O and (CoMgNiZn)O systems, the minimum required synthesis temperature in the former is much lower than that of the latter [130], further fortifying the theory of entropy stabilization. Hence, this theory has guided the research of highentropy oxides (HEOs) and has led to widespread recognition of the class of high-entropy ceramics.

Toward applications, HEOs can be used in the energy sector. For example, the (MgNiCoCuZn)O system exhibits a very high dielectric constant of $2 \times 10^{5}$ at $440 \mathrm{~K}$ with bulk resistance of $30 \mathrm{M} \Omega$ [131], as well as excellent lithium-ion conductivities with high capacity for lithium-ion batteries [132, 133, 134]. Doping this system with cations, such as Pt, results in high stability and compressibility [135], with good catalytic activity of CO oxidation [136]. The electrochemical properties, $\mathrm{CO}$ oxidation activity, and compressibility of the (MgNiCo$\mathrm{CuZn)O} \mathrm{system} \mathrm{are} \mathrm{shown} \mathrm{in} \mathrm{Fig.} \mathrm{12.} \mathrm{Unlike} \mathrm{crystalline} \mathrm{HEAs}$ with FCC, BCC, or occasionally HCP structures, HEOs can present much more complex structures, such as fluorite [137], perovskite [138] and rock salt structures [132]. Orthorhombic (Pbnm) perovskite HEOs, $\left(5 \mathrm{~A}_{0.2}\right)\left(5 \mathrm{~B}_{0.2}\right) \mathrm{O}_{3}$, show antiferromagnetic behaviors, due to a combination of an antiferromagnetic matrix and ferromagnetic clusters [139].

Next to HEOs, other high-entropy ceramics systems are under exploration as well, such as high-entropy diborides [140], carbides [141], silicides [142] and sulfides [143]. Both
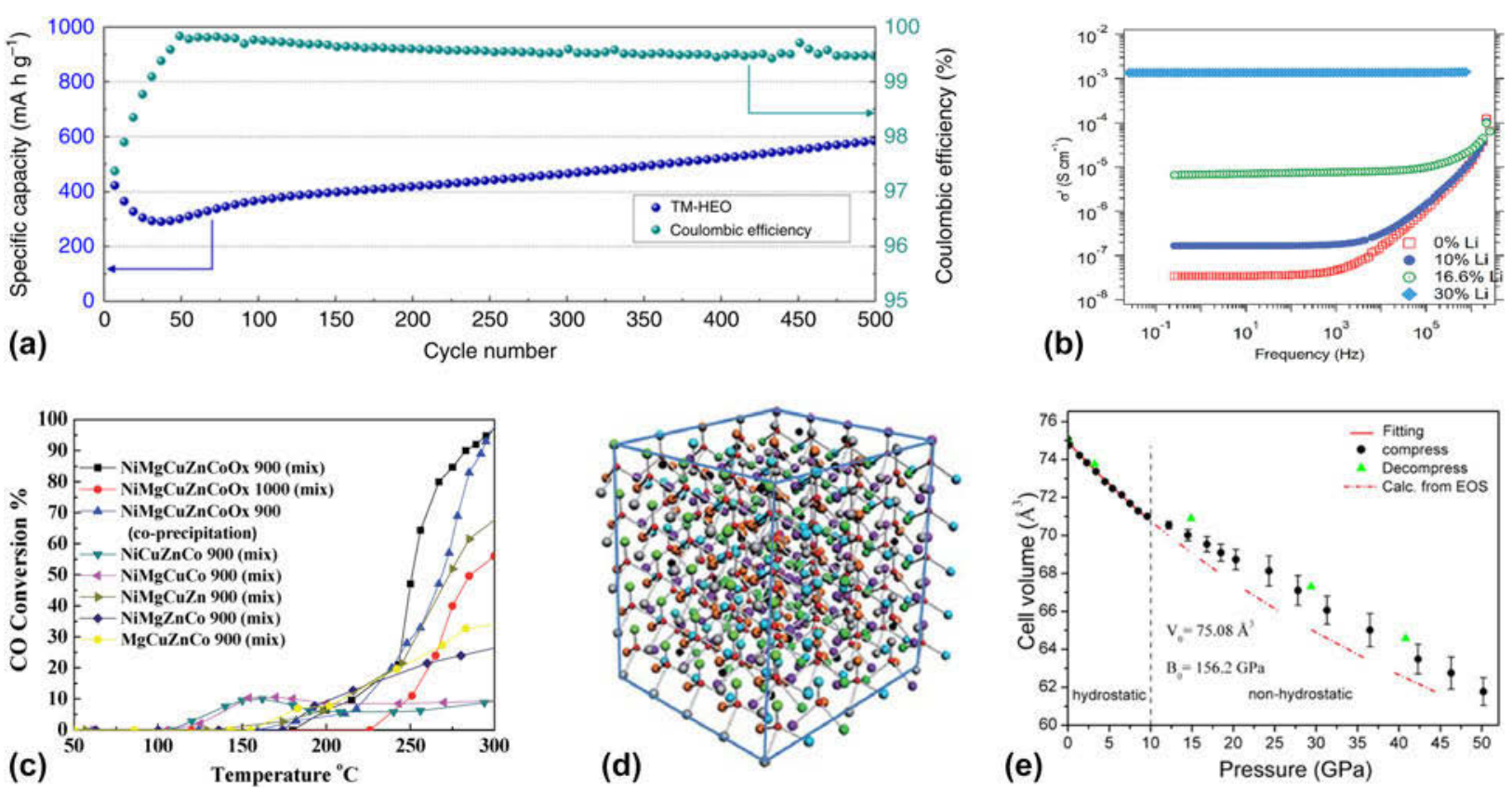

Figure 12: (a) Long-term cycling stability of (CoCuMgNiZn) $)_{0.2} \mathrm{O}$ with the corresponding Coulombic efficiency; (b) lithium superionic conductivity in ( $\mathrm{Mg}, \mathrm{Co}, \mathrm{Ni}$, $\mathrm{Cu}$, and $\mathrm{Zn})_{1-x} \mathrm{Li}_{x} \mathrm{O}$; (c) $\mathrm{CO}$ oxidation activity of $\mathrm{Pt}$-doped $\mathrm{NiMgCuZnCoO}_{x i}$ (d) structure of $\mathrm{NiMgCuZnCoO}_{x i}$ and (e) compressibility of $\mathrm{Li}_{\text {-doped }} \mathrm{MgCoNiCuZnO}_{5}$ (d). Figures (a) and (b) adapted from Refs. 134 and 133, respectively. Figures (c) and (d) adapted from Ref. 136 with permission from the Center National de la Recherche Scientifique (CNRS) and The Royal Society of Chemistry. Figure (e) reprinted (adapted) with permission from Ref. 135, Copyright 2019 from American Chemical Society. 
$\left(\mathrm{V}_{0.2} \mathrm{Nb}_{0.2} \mathrm{Ta}_{0.2} \mathrm{Mo}_{0.2} \mathrm{~W}_{0.2}\right) \mathrm{C}[141]$ and $\left(\mathrm{Hf}_{0.2} \mathrm{Zr}_{0.2} \mathrm{Ta}_{0.2} \mathrm{Cr}_{0.2} \mathrm{Ti}_{0.2}\right) \mathrm{B}_{2}$ [140] have been shown to be ideal systems for further investigation of entropy stabilization theory in high-entropy carbides and diborides, respectively. The $\left(\mathrm{Yb}_{0.25} \mathrm{Y}_{0.25} \mathrm{Lu}_{0.25} \mathrm{Er}_{0.25}\right)_{2} \mathrm{SiO}_{5}$ system not only presents significant anisotropy in thermal expansion but also provides a new theory on elemental configuration for high-entropy ceramics [144]. Furthermore, based on the entropy stabilization theory and configuration principle, a complete metallic-element system made up of IM compounds, such as $\left(\mathrm{Fe}_{0.2} \mathrm{Co}_{0.2} \mathrm{Ni}_{0.2} \mathrm{Mn}_{0.2} \mathrm{Cu}_{0.2}\right) \mathrm{Al}$, is also a promising research direction, providing a system that bridges the gap between HEAs and ceramics [145]. Nevertheless, recent investigations are mainly focused on fabrication methods, and the properties of these newly explored materials are much less studied. As a result, the effect of nanoscale structures on highentropy ceramics has not been well understood. Therefore, the combination of entropy stabilization theory and unique performance due to nanoscale grain sizes is interesting for future research.

\section{Summary, current challenges, and future opportunities}

\section{Summary}

In summary, this article has reviewed the recent literature on NC HEAs and NC HEMs. We have summarized the most popular methods used to synthesize NC HEAs and NC HEMs as MA (more specifically, ball milling), followed by HPT and DCMS. Of these three, HPT has been shown to have the highest success rate in forming single-phase alloys. Although we have not found conclusive trends in mechanical or functional properties that support current theories surrounding HEMs, there are many useful properties that can be extracted from such materials. In general, NC HEAs are stronger than coarse-grained HEAs and NC metals/alloys, and their thermal stability generally surpasses pure and binary NC materials. NC HEAs can be regarded as promising candidates for wear resistance, whereas they seem to be less ideal for the corrosion resistance. Through modifications in synthesis techniques and compositions, nanostructures can be optimized for specific functional properties. Although nanostructures result in high impedance to electron movement, their synergetic influence with high lattice distortion in NC HEAs leads to promising thermoelectric properties. Additionally, the transition of nanostructures can also affect the types of magnetism of NC HEAs. We also see an ever-increasing expansion in the breadth of HEMs being studied, from the more conventional $3 \mathrm{~d}$ transition metal group, to oxides, nitrides, glasses, composites, and many more. The mechanical studies of NC HEAs and HEMs have been intensively focused on hardness, tensile strength, and ductility. However, the fracture toughness, creep resistance, and fatigue properties of such NC HEAs have been relatively rarely reported up to date.

\section{Current challenges}

Further development in this field is hindered primarily by the limitation of methods and suitable materials. If the motivation to develop new NC HEAs is to replace conventional alloys, such as stainless steels and Ni-based superalloys, and provide superior mechanical and functional properties, the development of more suitable HEM candidates with low cost and good scalability should be considered at the early stage of materials design. Industrial viability must also be measured by the potential applications of these materials, which are currently narrow and specific to very few alloys. A second, and widespread, challenge impeding HEM research, is that searching the appropriate compositions out of the huge compositional space is an arduous task. However, there is little potential toward simulating HEMs, as their complexity lends them to oftentimes form structures and properties that are unexpected and unpredictable. Furthermore, the methods used to make NC HEMs are very limited and it is also challenging to scale up the sample size using current processing methods. Consequently, it is challenging to test many mechanical and functional properties, such as fracture toughness and fatigue, toward practical applications. Finally, the thermodlynamic and kinetic models for NC metals and binary alloys may not be directly applied to NC HEAs/HEMs; new theories are expected to be developed to give a better understanding of mechanical and functional behavior in NC HEAs/HEMs.

\section{Future opportunities}

The outlook on NC-HEM research is not entirely grim, as many of the promising opportunities in this field stem directly from these challenges. Much effort has gone toward the improvement of mechanical and thermal stability of HEMs, and many through novel methods and structures. As such, the contributions of HEA studies are not only restricted to this field but also to the whole metallurgy and materials science community. Furthermore, the expansion of this research outlook to include not only HEAs but all HEMs could help to drive more innovative research as well.

HEAs and HEMs are often classified as fields in which high throughput experimentation is required to fully explore the compositional landscape of available alloy/material combinations. On the other side of this coin is the vast expanse of functional properties that a single material could exhibit, which itself requires high-throughput experimentation to fully explore. If we consider the approximate number of unique alloys $(\sim 75)$, processes (11), and properties (9) reviewed in this article, to fully investigate the comparative performance of each alloy we arrive 
at minimum of $\sim 7500$ separate characterization studies that must be performed, not including those alloys with the same composition but different microstructures. The time and cost to obtain this information is huge, and not altogether certain to give the results that are desired. Conventionally, the identification of new HEMs with desired structures and properties out of a vast compositional space is a daunting task through a sequential, slow, and trial-and-error approach. A prospective time- and cost-saving approach to acquiring this information is the use of machine learning (ML). As a tool to accompany physical testing, ML can be very useful in accelerating the discovery of new HEM candidates for various engineering applications. It would be of benefit to the HEM, and even broader material community, that a new methodology inverts the traditional paradigm. Such a new closed-loop paradigm may require incorporating material design, ML screening, high-throughput fabrication, characterization, and testing into an integrated system.

\section{Acknowledgments}

This work was developed with the financial support from the Discovery Grants Program (RGPIN-2018-05731) of the Natural Sciences and Engineering Research Council of Canada (NSERC) and Dean's Spark Assistant Professorship in the Faculty of Applied Science \& Engineering at the University of Toronto.

\section{Supplementary material}

To view supplementary material for this article, please visit https://doi.org/10.1557/jmr.2020.33.

\section{References}

1. J-W. Yeh, S-K. Chen, S-J. Lin, J-Y. Gan, T-S. Chin, T-T. Shun, C-H. Tsau, and S-Y. Chang: Nanostructured high-entropy alloys with multiple principal elements: Novel alloy design concepts and outcomes. Adv. Eng. Mater. 6, 299 (2004).

2. D.B. Miracle and O.N. Senkov: A critical review of high entropy alloys and related concepts. Acta Mater. 122, 448 (2017).

3. M-H. Tsai and J-W. Yeh: High-entropy alloys: A critical review. Mater. Res. Lett. 2, 107 (2014).

4. H. Gleiter: Nanocrystalline materials. Prog. Mater. Sci. 33, 223 (1989).

5. C.C. Koch, ed.: Nanostructured Materials: Processing, Properties, and Applications, 2nd ed. (William Andrew Publisher, Norwich, NY, 2007).

6. J. Weissmüller: Alloy effects in nanostructures. Nanostruct. Mater. 3, 261 (1993).

7. J. Weissmüller: Alloy thermodynamics in nanostructures. J. Mater. Res. 9, 4 (1994).

8. J-W. Yeh: Recent progress in high-entropy alloys. Ann. Chimie Sci. Matériaux 31, 633 (2006).
9. R.L. Fleischer: Substitutional solution hardening. Acta Metall. 11, 203 (1963).

10. R. Labusch: A statistical theory of solid solution hardening. Phys. Status Solidi B 41, 659 (1970).

11. L.A. Gypen and A. Deruyttere: Multi-component solid solution hardening. J. Mater. Sci. 12, 1028 (1977)

12. I. Toda-Caraballo and P.E.J. Rivera-Díaz-del-Castillo: Modelling solid solution hardening in high entropy alloys. Acta Mater. 85, 14 (2015).

13. E.O. Hall: The deformation and ageing of mild steel: III discussion of results. Proc. Phys. Soc. Sect. B 64, 747 (1951).

14. N.J. Petch: The cleavage strength of polycrystals. Iron Steel Inst., 174, 25 (1953).

15. J. Luo and Z.R. Wang: On the physical meaning of the HallPetch constant. Adv. Mater. Res. 15-17, 643 (2006).

16. C.E. Carlton and P.J. Ferreira: What is behind the inverse Hall-Petch effect in nanocrystalline materials? Acta Mater. 55, 3749 (2007).

17. G. Gottstein and L.S. Shvindlerman: Grain Boundary Migration in Metals: Thermodynamics, Kinetics, Applications, 2nd ed. (CRC Press-Taylor \& Francis Group, Boca Raton, FL, 2010).

18. D.A. Porter, K.E. Easterling, and M.Y. Sherif: Phase Transformations in Metals and Alloys, 3rd ed. (CRC PressTaylor \& Francis Group, Boca Raton, FL, 2009).

19. Y. Zou, H. Ma, and R. Spolenak: Ultrastrong ductile and stable high-entropy alloys at small scales. Nat. Commun. 6 (2015)

20. W.H. Liu, Y. Wu, J.Y. He, T.G. Nieh, and Z.P. Lu: Grain growth and the Hall-Petch relationship in a high-entropy FeCrNiCoMn alloy. Scr. Mater. 68, 526 (2013).

21. R. Sriharitha, B.S. Murty, and R.S. Kottada: Alloying, thermal stability and strengthening in spark plasma sintered $\mathrm{Al}_{x} \mathrm{CoCrCuFeNi}$ high entropy alloys. J. Alloys Compd. 583, 419 (2014).

22. P. Sathiyamoorthi, J. Basu, S. Kashyap, K.G. Pradeep, and R.S. Kottada: Thermal stability and grain boundary strengthening in ultrafine-grained CoCrFeNi high entropy alloy composite. Mater. Des. 134, 426 (2017).

23. R.Z. Valiev: Producing bulk nanostructured metals and alloys by severe plastic deformation (SPD), Nanostructured Metals and Alloys-Processing, Microstructure, Mechanical Properties, and Applications, S.H. Wang, ed. (Woodhead Publishing Ltd., Cambridge, U.K., 2011); pp. 1-39.

24. Y. Long, K. Su, J. Zhang, X. Liang, H. Peng, and X. Li: Enhanced strength of a mechanical alloyed NbMoTaWVTi refractory high entropy alloy. Materials 11, 669 (2018).

25. T. Lu, S. Scudino, W. Chen, P. Wang, D. Li, M. Mao, L. Kang, Y. Liu, and $\mathrm{Z}$. Fu: The influence of nanocrystalline CoNiFeAl $\mathrm{A}_{0.4} \mathrm{Ti}_{0.6} \mathrm{Cr}_{0.5}$ high-entropy alloy particles addition on microstructure and mechanical properties of $\mathrm{SiC}_{\mathrm{p}} / 7075 \mathrm{Al}$ composites. Mater. Sci. Eng., A 726, 126 (2018).

26. N. Kumar, C.S. Tiwary, and K. Biswas: Preparation of nanocrystalline high-entropy alloys via cryomilling of cast ingots. J. Mater. Sci. 53, 13411 (2018). 
27. K.M. Youssef, A.J. Zaddach, C. Niu, D.L. Irving, and C.C. Koch: A novel low-density, high-hardness, high-entropy alloy with close-packed single-phase nanocrystalline structures. Mater. Res. Lett. 3, 95 (2015).

28. R.M. Pohan, B. Gwalani, J. Lee, T. Alam, J.Y. Hwang, H.J. Ryu,

R. Banerjee, and S.H. Hong: Microstructures and mechanical properties of mechanically alloyed and spark plasma sintered $\mathrm{Al}_{0.3} \mathrm{CoCrFeMnNi}$ high entropy alloy. Mater. Chem. Phys. 210, 62 (2018).

29. P. Wang, H. Cai, and $\mathrm{X}$. Cheng: Effect of $\mathrm{Ni} / \mathrm{Cr}$ ratio on phase, microstructure and mechanical properties of $\mathrm{Ni}_{x} \mathrm{CoCuFeCr}_{2-x}(x$ $=1.0,1.2,1.5,1.8 \mathrm{~mol}$ ) high entropy alloys. J. Alloys Compd. 662, 20 (2016).

30. S. Praveen, B.S. Murty, and R.S. Kottada: Alloying behavior in multi-component AlCoCrCuFe and $\mathrm{NiCoCrCuFe}$ high entropy alloys. Mater. Sci. Eng., A 534, 83 (2012).

31. H. Shahmir, J. He, Z. Lu, M. Kawasaki, and T.G. Langdon: Effect of annealing on mechanical properties of a nanocrystalline CoCrFeNiMn high-entropy alloy processed by high-pressure torsion. Mater. Sci. Eng., A 676, 294 (2016).

32. D-H. Lee, I-C. Choi, M-Y. Seok, J. He, Z. Lu, J-Y. Suh, M. Kawasaki, T.G. Langdon, and J. Jang: Nanomechanical behavior and structural stability of a nanocrystalline CoCrFeNiMn high-entropy alloy processed by high-pressure torsion. J. Mater. Res. 30, 2804 (2015).

33. X.B. Feng, J.Y. Zhang, Y.Q. Wang, Z.Q. Hou, K. Wu, G. Liu, and J. Sun: Size effects on the mechanical properties of nanocrystalline NbMoTaW refractory high entropy alloy thin films. Int. J. Plast. 95, 264 (2017).

34. T. Nagase, P.D. Rack, J.H. Noh, and T. Egami: In situ TEM observation of structural changes in nano-crystalline $\mathrm{CoCrCuFeNi}$ multicomponent high-entropy alloy (HEA) under fast electron irradiation by high voltage electron microscopy (HVEM). Intermetallics 59, 32 (2015).

35. T.K. Chen, T.T. Shun, J.W. Yeh, and M.S. Wong: Nanostructured nitride films of multi-element high-entropy alloys by reactive DC sputtering. Surf. Coat. Technol. 188-189, 193 (2004).

36. W. Liao, S. Lan, L. Gao, H. Zhang, S. Xu, J. Song, X. Wang, and Y. Lu: Nanocrystalline high-entropy alloy (CoCrFeNiAl $\left.0_{0.3}\right)$ thin-film coating by magnetron sputtering. Thin Solid Films 638, 383 (2017).

37. Y-L. Chen, Y-H. Hu, C-W. Tsai, C-A. Hsieh, S-W. Kao, J-W. Yeh, T-S. Chin, and S-K. Chen: Alloying behavior of binary to octonary alloys based on $\mathrm{Cu}-\mathrm{Ni}-\mathrm{Al}-\mathrm{Co}-\mathrm{Cr}-\mathrm{Fe}-\mathrm{Ti}-\mathrm{Mo}$ during mechanical alloying. J. Alloys Compd. 477, 696 (2009).

38. Q. Lin, X. An, H. Liu, Q. Tang, P. Dai, and X. Liao: In-situ high-resolution transmission electron microscopy investigation of grain boundary dislocation activities in a nanocrystalline CrMnFeCoNi high-entropy alloy. J. Alloys Compd. 709, 802 (2017).
39. H. Kim, S. Nam, A. Roh, M. Son, M-H. Ham, J-H. Kim, and H. Choi: Mechanical and electrical properties of NbMoTaW refractory high-entropy alloy thin films. Int. J. Refract. Met. Hard Mater. 80, 286 (2019).

40. S.A. Firstov, V.F. Gorban', N.I. Danilenko, M.V. Karpets,

A.A. Andreev, and E.S. Makarenko: Thermal stability of superhard nitride coatings from high-entropy multicomponent $\mathrm{Ti}-\mathrm{V}-\mathrm{Zr}-\mathrm{Nb}-$ Hf alloy. Powder Metall. Met. Ceram. 52, 560 (2014).

41. O.V. Sobol', A.A. Andreev, V.F. Gorban', N.A. Krapivka, V.A. Stolbovoi, I.V. Serdyuk, and V.E. Fil'chikov: Reproducibility of the single-phase structural state of the multielement high-entropy $\mathrm{Ti}-\mathrm{V}-\mathrm{Zr}-\mathrm{Nb}-\mathrm{Hf}$ system and related superhard nitrides formed by the vacuum-arc method. Tech. Phys. Lett. 38, 616 (2012).

42. B. Schuh, B. Völker, J. Todt, N. Schell, L. Perrière, J. Li, J.P. Couzinié, and A. Hohenwarter: Thermodynamic instability of a nanocrystalline, single-phase TiZrNbHfTa alloy and its impact on the mechanical properties. Acta Mater. 142, 201 (2018).

43. B. Schuh, B. Völker, V. Maier-Kiener, J. Todt, J. Li, and A. Hohenwarter: Phase decomposition of a single-phase AlTiVNb high-entropy alloy after severe plastic deformation and annealing: Phase decomposition of a single-phase AlTiVNb highentropy alloy. Adv. Eng. Mater. 19, 1600674 (2017).

44. Ł. Rogal, D. Kalita, A. Tarasek, P. Bobrowski, and F. Czerwinski: Effect of $\mathrm{SiC}$ nano-particles on microstructure and mechanical properties of the $\mathrm{CoCrFeMnNi}$ high entropy alloy. J. Alloys Compd. 708, 344 (2017).

45. H. Shahmir, E. Tabachnikova, A. Podolskiy, M. Tikhonovsky, and T.G. Langdon: Effect of carbon content and annealing on structure and hardness of $\mathrm{CrFe}_{2} \mathrm{NiMnV}_{0.25}$ high-entropy alloys processed by high-pressure torsion. J. Mater. Sci. 53, 11813 (2018).

46. H. Shahmir, M. Nili-Ahmadabadi, A. Shafiee, M. Andrzejczuk,

M. Lewandowska, and T.G. Langdon: Effect of Ti on phase stability and strengthening mechanisms of a nanocrystalline CoCrFeMnNi high-entropy alloy. Mater. Sci. Eng., A 725, 196 (2018).

47. Y. Xie, H. Cheng, Q. Tang, W. Chen, W. Chen, and P. Dai: Effects of $\mathrm{N}$ addition on microstructure and mechanical properties of CoCrFeNiMn high entropy alloy produced by mechanical alloying and vacuum hot pressing sintering. Intermetallics 93, 228 (2018).

48. P. Wang, X. Cheng, H. Cai, Y. Xue, and Y. Zhang: Influence of increasing $\mathrm{Al}$ concentration on phase, microstructure and mechanical behaviors of $\mathrm{Ni}_{1.5} \mathrm{CoFeCu}_{1-x} \mathrm{Al}_{x} \mathrm{~V}_{0.5}$ high entropy alloys. Mater. Sci. Eng., A 708, 523 (2017).

49. Ł. Rogal, D. Kalita, and L. Litynska-Dobrzynska: CoCrFeMnNi high entropy alloy matrix nanocomposite with addition of $\mathrm{Al}_{2} \mathrm{O}_{3}$. Intermetallics 86, 104 (2017).

50. H. Shahmir, M. Nili-Ahmadabadi, A. Shafie, and T. Langdon Hardening and thermal stability of a nanocrystalline $\mathrm{CoCrFeNiMnTi} \mathrm{i}_{0.1}$ high-entropy alloy processed by high-pressure torsion. IOP Conf. Ser.: Mater. Sci. Eng. 194, 012017 (2017). 
51. C. Shang, E. Axinte, J. Sun, X. Li, P. Li, J. Du, P. Qiao, and Y. Wang: CoCrFeNi $\left(\mathrm{W}_{1-x} \mathrm{Mo}_{x}\right)$ high-entropy alloy coatings with excellent mechanical properties and corrosion resistance prepared by mechanical alloying and hot pressing sintering. Mater. Des. 117, 193 (2017).

52. O. Maulik, D. Kumar, S. Kumar, D.M. Fabijanic, and

V. Kumar: Structural evolution of spark plasma sintered $\operatorname{AlFeCuCrMg}_{x}(x=0,0.5,1,1.7)$ high entropy alloys. Intermetallics 77, 46 (2016).

53. C.D. Gómez-Esparza, F. Baldenebro-López, L. GonzálezRodelas, J. Baldenebro-López, and R. Martínez-Sánchez: Series of nanocrystalline $\mathrm{NiCoAlFe}(\mathrm{Cr}, \mathrm{Cu}, \mathrm{Mo}, \mathrm{Ti})$ high-entropy alloys produced by mechanical alloying. Mater. Res. 19, 39 (2016).

54. Z. Fu, W. Chen, H. Wen, D. Zhang, Z. Chen, B. Zheng, Y. Zhou, and E.J. Lavernia: Microstructure and strengthening mechanisms in an FCC structured single-phase nanocrystalline $\mathrm{Co}_{25} \mathrm{Ni}_{25} \mathrm{Fe}_{25} \mathrm{Al}_{7.5} \mathrm{Cu}_{17.5}$ high-entropy alloy. Acta Mater. 107, 59 (2016).

55. P.F. Yu, L.J. Zhang, H. Cheng, H. Zhang, M.Z. Ma, Y.C. Li, G. Li, P.K. Liaw, and R.P. Liu: The high-entropy alloys with high hardness and soft magnetic property prepared by mechanical alloying and high-pressure sintering. Intermetallics 70, 82 (2016).

56. P.F. Yu, H. Cheng, L.J. Zhang, H. Zhang, Q. Jing, M.Z. Ma, P.K. Liaw, G. Li, and R.P. Liu: Effects of high pressure torsion on microstructures and properties of an $\mathrm{Al}_{0.1} \mathrm{CoCrFeNi}$ highentropy alloy. Mater. Sci. Eng., A 655, 283 (2016).

57. H. Khanchandani, P. Sharma, R. Kumar, O. Maulik, and V. Kumar: Effect of sintering on phase evolution in AlMgFeCuCrNi ${ }_{4.75}$ high entropy alloy. Adv. Powder Technol. 27, 289 (2016).

58. B. Schuh, F. Mendez-Martin, B. Völker, E.P. George,

H. Clemens, R. Pippan, and A. Hohenwarter: Mechanical properties, microstructure and thermal stability of a nanocrystalline CoCrFeMnNi high-entropy alloy after severe plastic deformation. Acta Mater. 96, 258 (2015).

59. Q.H. Tang, Y. Huang, Y.Y. Huang, X.Z. Liao, T.G. Langdon, and P.Q. Dai: Hardening of an $\mathrm{Al}_{0.3} \mathrm{CoCrFeNi}$ high entropy alloy via high-pressure torsion and thermal annealing. Mater. Lett. 151, 126 (2015).

60. W. Ji, W. Wang, H. Wang, J. Zhang, Y. Wang, F. Zhang, and Z. Fu: Alloying behavior and novel properties of CoCrFeNiMn high-entropy alloy fabricated by mechanical alloying and spark plasma sintering. Intermetallics 56, 24 (2015).

61. S. Mohanty, N.P. Gurao, and K. Biswas: Sinter ageing of equiatomic $\mathrm{Al}_{20} \mathrm{Co}_{20} \mathrm{Cu}_{20} \mathrm{Zn}_{20} \mathrm{Ni}_{20}$ high entropy alloy via mechanical alloying. Mater. Sci. Eng., A 617, 211 (2014).

62. C. Wang, W. Ji, and Z. Fu: Mechanical alloying and spark plasma sintering of CoCrFeNiMnAl high-entropy alloy. $A d v$. Powder Technol. 25, 1334 (2014).

63. W. Ji, Z. Fu, W. Wang, H. Wang, J. Zhang, Y. Wang, and F. Zhang: Mechanical alloying synthesis and spark plasma sintering consolidation of CoCrFeNiAl high-entropy alloy. $J$. Alloys Compd. 589, 61 (2014).

64. S. Praveen, B.S. Murty, and R.S. Kottada: Phase evolution and densification behavior of nanocrystalline multicomponent high entropy alloys during spark plasma sintering. JOM 65, 1797 (2013).

65. K.G. Pradeep, N. Wanderka, P. Choi, J. Banhart, B.S. Murty, and D. Raabe: Atomic-scale compositional characterization of a nanocrystalline $\mathrm{AlCrCuFeNiZn} \mathrm{high-entropy} \mathrm{alloy} \mathrm{using} \mathrm{atom}$ probe tomography. Acta Mater. 61, 4696 (2013).

66. S.D Washko and G. Aggen: "Wrought Stainless Steels" ASM Handbook-Volume 1: Properties and Selection: Irons, Steels, and High-Performance Alloys (ASM International, 1993).

67. N.S Stoloff: "Wrought and P/M Superalloys" ASM HandbookVolume 1: Properties and Selection: Irons, AU3 Steels, and HighPerformance Alloys (ASM International, 1993).

68. A.J. Zaddach, C. Niu, C.C. Koch, and D.L. Irving: Mechanical properties and stacking fault energies of NiFeCrCoMn highentropy alloy. JOM 65, 1780 (2013).

69. N.L. Okamoto, S. Fujimoto, Y. Kambara, M. Kawamura, Z.M.T. Chen, H. Matsunoshita, K. Tanaka, H. Inui, and E.P. George: Size effect, critical resolved shear stress, stacking fault energy, and solid solution strengthening in the CrMnFeCoNi high-entropy alloy. Sci. Rep. 6, 35863 (2016).

70. S. Yoshida, T. Ikeuchi, T. Bhattacharjee, Y. Bai, A. Shibata, and N. Tsuji: Effect of elemental combination on friction stress and Hall-Petch relationship in face-centered cubic high/medium entropy alloys. Acta Mater. 171, 201 (2019).

71. C. Keller and E. Hug: Hall-Petch behaviour of Ni polycrystals with a few grains per thickness. Mater. Lett. 62, 1718 (2008).

72. S. Yoshida, T. Bhattacharjee, Y. Bai, and N. Tsuji: Friction stress and Hall-Petch relationship in CoCrNi equi-atomic medium entropy alloy processed by severe plastic deformation and subsequent annealing. Scr. Mater. 134, 33 (2017).

73. F. Otto, A. Dlouhý, C. Somsen, H. Bei, G. Eggeler, and E.P. George: The influences of temperature and microstructure on the tensile properties of a CoCrFeMnNi high-entropy alloy. Acta Mater. 61, 5743 (2013).

74. N. Hansen and B. Ralph: The strain and grain size dependence of the flow stress of copper. Acta Metall. 30, 411 (1982).

75. L.J. Yang: Wear coefficient equation for aluminium-based matrix composites against steel disc. Wear 255, 579 (2003).

76. Y-F. Kao, T-J. Chen, S-K. Chen, and J-W. Yeh: Microstructure and mechanical property of as-cast, -homogenized, and -deformed $\mathrm{Al}_{x} \mathrm{CoCrFeNi}(0 \leq x \leq 2)$ high-entropy alloys. $J$. Alloys Compd. 488, 57 (2009).

77. W-R. Wang, W-L. Wang, and J-W. Yeh: Phases, microstructure and mechanical properties of $\mathrm{Al}_{x} \mathrm{CoCrFeNi}$ high-entropy alloys at elevated temperatures. J. Alloys Compd. 589, 143 (2014).

78. J-M. Wu, S-J. Lin, J-W. Yeh, S-K. Chen, Y-S. Huang, and H-C. Chen: Adhesive wear behavior of $\mathrm{Al}_{x} \mathrm{CoCrCuFeNi}$ high-entropy alloys as a function of aluminum content. Wear 261, 513 (2006). 
79. M-R. Chen, S-J. Lin, J-W. Yeh, S-K. Chen, Y-S. Huang, and C-P. Tu: Microstructure and properties of $\mathrm{Al}_{0.5} \mathrm{CoCrCuFeNiTi}_{x}$ $(x=0-2.0)$ high-entropy alloys. Mater. Trans. 47, 1395 (2006).

80. C. Shang, E. Axinte, W. Ge, Z. Zhang, and Y. Wang: Highentropy alloy coatings with excellent mechanical, corrosion resistance and magnetic properties prepared by mechanical alloying and hot pressing sintering. Surf. Interfaces 9, 36 (2017).

81. N. Zhou, T. Hu, J. Huang, and J. Luo: Stabilization of nanocrystalline alloys at high temperatures via utilizing highentropy grain boundary complexions. Scr. Mater. 124, 160 (2016).

82. H. Zhang, Y-Z. He, Y. Pan, and S. Guo: Thermally stable laser cladded CoCrCuFeNi high-entropy alloy coating with low stacking fault energy. J. Alloys Compd. 600, 210 (2014).

83. S. Mohanty, T.N. Maity, S. Mukhopadhyay, S. Sarkar,

N.P. Gurao, S. Bhowmick, and K. Biswas: Powder metallurgical processing of equiatomic $\mathrm{AlCoCrFeNi}$ high entropy alloy: Microstructure and mechanical properties. Mater. Sci. Eng., A 679, 299 (2017).

84. D. Kumar, O. Maulik, S. Kumar, Y.V.S.S. Prasad, and V. Kumar: Phase and thermal study of equiatomic $\mathrm{AlCuCrFeMnW}$ high entropy alloy processed via spark plasma sintering. Mater. Chem. Phys. 210, 71 (2018).

85. A.S. Sharma, S. Yadav, K. Biswas, and B. Basu: High-entropy alloys and metallic nanocomposites: Processing challenges, microstructure development and property enhancement. Mater. Sci. Eng., $R$ 131, 1 (2018).

86. H-P. Chou, Y-S. Chang, S-K. Chen, and J-W. Yeh: Microstructure, thermophysical and electrical properties in $\mathrm{Al}_{x} \mathrm{CoCrFeNi}(0 \leq x \leq 2)$ high-entropy alloys. Mater. Sci. Eng. B 163, 184 (2009).

87. S. Shafeie, S. Guo, Q. Hu, H. Fahlquist, P. Erhart, and A. Palmqvist: High-entropy alloys as high-temperature thermoelectric materials. J. Appl. Phys. 118, 184905 (2015).

88. R. Wang, K. Zhang, C. Davies, and X. Wu: Evolution of microstructure, mechanical and corrosion properties of AlCoCrFeNi high-entropy alloy prepared by direct laser fabrication. J. Alloys Compd. 694, 971 (2017).

89. W. Dong, Z. Zhou, L. Zhang, M. Zhang, P. Liaw, G. Li, and R. Liu: Effects of $\mathrm{Y}, \mathrm{GdCu}$, and $\mathrm{Al}$ addition on the thermoelectric behavior of CoCrFeNi high entropy alloys. Metals 8, 781 (2018).

90. Y. Shi, L. Collins, R. Feng, C. Zhang, N. Balke, P.K. Liaw, and B. Yang: Homogenization of $\mathrm{Al}_{x} \mathrm{CoCrFeNi}$ high-entropy alloys with improved corrosion resistance. Corros. Sci. 133, 120 (2018).

91. Y-F. Kao, S-K. Chen, T-J. Chen, P-C. Chu, J-W. Yeh, and S-J. Lin: Electrical, magnetic, and Hall properties of $\mathrm{Al}_{x} \mathrm{CoCrFeNi}$ high-entropy alloys. J. Alloys Compd. 509, 1607 (2011).

92. K.D. Ralston and N. Birbilis: Effect of grain size on corrosion: A review. CORROSION 66, 075005 (2010).

93. R. Rofagha, R. Langer, A.M. El-Sherik, U. Erb, G. Palumbo, and K.T. Aust: The corrosion behaviour of nanocrystalline nickel. Scr. Metall. Mater. 25, 2867 (1991).
94. L. Monaco, G. Avramovic-Cingara, G. Palumbo, and U. Erb: Corrosion behaviour of electrodeposited nanocrystalline nickeliron (NiFe) alloys in dilute $\mathrm{H}_{2} \mathrm{SO}_{4}$. Corros. Sci. 130, 103 (2018).

95. Y. Qiu, S. Thomas, M.A. Gibson, H.L. Fraser, and N. Birbilis: Corrosion of high entropy alloys. npj Mater. Degrad. 1, 15 (2017).

96. Y. Shi, B. Yang, and P. Liaw: Corrosion-resistant high-entropy alloys: A review. Metals 7, 43 (2017).

97. J. Li, X. Yang, R. Zhu, and Y. Zhang: Corrosion and serration behaviors of $\mathrm{TiZr}_{0.5} \mathrm{NbCr}_{0.5} \mathrm{~V}_{x} \mathrm{Mo}_{y}$ high entropy alloys in aqueous environments. Metals 4, 597 (2014).

98. C-Y. Hsu, J-W. Yeh, S-K. Chen, and T-T. Shun: Wear resistance and high-temperature compression strength of FCC $\mathrm{CuCoNiCrAl}_{0.5} \mathrm{Fe}$ alloy with boron addition. Metall. Mater. Trans. A 35, 1465 (2004).

99. Y.Y. Chen, T. Duval, U.D. Hung, J.W. Yeh, and H.C. Shih: Microstructure and electrochemical properties of high entropy alloys-A comparison with type-304 stainless steel. Corros. Sci. 47, 2257 (2005).

100. Z. Nong, J. Zhu, X. Yang, H. Yu, and Z. Lai: Effects of annealing on microstructure, mechanical and electrical properties of AlCrCuFeMnTi high entropy alloy. J. Wuhan Univ. Technol., Mater. Sci. Ed. 28, 1196 (2013).

101. F. von Rohr, M.J. Winiarski, J. Tao, T. Klimczuk, and R.J. Cava: Effect of electron count and chemical complexity in the Ta-Nb-Hf-Zr-Ti high-entropy alloy superconductor. Proc. Natl. Acad. Sci. 113, E7144 (2016)

102. F.O. von Rohr and R.J. Cava: Isoelectronic substitutions and aluminium alloying in the $\mathrm{Ta}-\mathrm{Nb}-\mathrm{Hf}-\mathrm{Zr}$ - Ti high-entropy alloy superconductor. Phys. Rev. Mater. 2, 034801 (2018).

103. A. Karati, M. Nagini, S. Ghosh, R. Shabadi, K.G. Pradeep, R.C. Mallik, B.S. Murty, and U.V. Varadaraju: Ti2NiCoSnSb-A new half-Heusler type high-entropy alloy showing simultaneous increase in Seebeck coefficient and electrical conductivity for thermoelectric applications. Sci. Rep. 9, 5331 (2019).

104. R. Liu, H. Chen, K. Zhao, Y. Qin, B. Jiang, T. Zhang, G. Sha X. Shi, C. Uher, W. Zhang, and L. Chen: Entropy as a gene-like performance indicator promoting thermoelectric materials. Adv. Mater. 29, 1702712 (2017).

105. J. Yan, F. Liu, G. Ma, B. Gong, J. Zhu, X. Wang, W. Ao, C. Zhang, Y. Li, and J. Li: Suppression of the lattice thermal conductivity in NbFeSb-based half-Heusler thermoelectric materials through high entropy effects. Scr. Mater. 157, 129 (2018).

106. G. Tan, F. Shi, S. Hao, H. Chi, T.P. Bailey, L-D. Zhao, C. Uher, C. Wolverton, V.P. Dravid, and M.G. Kanatzidis: Valence band modification and high thermoelectric performance in $\mathrm{SnTe}$ heavily alloyed with MnTe. J. Am. Chem. Soc. 137, 11507 (2015)

107. L. Hu, Y. Zhang, H. Wu, J. Li, Y. Li, M. McKenna, J. He, F. Liu, S.J. Pennycook, and X. Zeng: Entropy engineering of SnTe: Multi-principal-element alloying leading to ultralow lattice thermal conductivity and state-of-the-art thermoelectric performance. Adv. Energy Mater. 8, 1802116 (2018). 
108. C-Z. Yao, P. Zhang, M. Liu, G-R. Li, J-Q. Ye, P. Liu, and Y-X. Tong: Electrochemical preparation and magnetic study of Bi-Fe-Co-Ni-Mn high entropy alloy. Electrochim. Acta 53, 8359 (2008).

109. Q. Luo, D.Q. Zhao, M.X. Pan, and W.H. Wang: Magnetocaloric effect in Gd-based bulk metallic glasses. Appl. Phys. Lett. 89, 081914 (2006)

110. Y. Yuan, Y. Wu, X. Tong, H. Zhang, H. Wang, X.J. Liu, L. Ma, H.L. Suo, and Z.P. Lu: Rare-earth high-entropy alloys with giant magnetocaloric effect. Acta Mater. 125, 481 (2017).

111. M. Sahlberg, D. Karlsson, C. Zlotea, and U. Jansson: Superior hydrogen storage in high entropy alloys. Sci. Rep. 6, 36770 (2016).

112. J. Hu, H. Shen, M. Jiang, H. Gong, H. Xiao, Z. Liu, G. Sun, and X. Zu: A DFT study of hydrogen storage in high-entropy alloy TiZrHfScMo. Nanomaterials 9, 461 (2019).

113. S.B. Gesari, M.E. Pronsato, A. Visintin, and A. Juan: Hydrogen storage in $\mathrm{AB}_{2}$ laves phase $(\mathrm{A}=\mathrm{Zr}, \mathrm{Ti} ; \mathrm{B}=\mathrm{Ni}, \mathrm{Mn}, \mathrm{Cr}, \mathrm{V})$ : Binding energy and electronic structure. J. Phys. Chem. C 114, 16832 (2010).

114. H. Luo, Z. Li, and D. Raabe: Hydrogen enhances strength and ductility of an equiatomic high-entropy alloy. Sci. Rep. 7, 9892 (2017).

115. Y. Zhao, D-H. Lee, M-Y. Seok, J-A. Lee, M.P. Phaniraj, J-Y. Suh, H-Y. Ha, J-Y. Kim, U. Ramamurty, and J-I. Jang: Resistance of CoCrFeMnNi high-entropy alloy to gaseous hydrogen embrittlement. Scr. Mater. 135, 54 (2017).

116. B. Gludovatz, A. Hohenwarter, D. Catoor, E.H. Chang, E.P. George, and R.O. Ritchie: A fracture-resistant high-entropy alloy for cryogenic applications. Science 345, 1153 (2014).

117. Z. Wu, C.M. Parish, and H. Bei: Nano-twin mediated plasticity in carbon-containing FeNiCoCrMn high entropy alloys. J. Alloys Compd. 647, 815 (2015).

118. H. Idrissi, L. Ryelandt, M. Veron, D. Schryvers, and P.J. Jacques: Is there a relationship between the stacking fault character and the activated mode of plasticity of Fe-Mn-based austenitic steels? Scr. Mater. 60, 941 (2009).

119. Y.H. Zhang, Y. Zhuang, A. Hu, J.J. Kai, and C.T. Liu: The origin of negative stacking fault energies and nano-twin formation in face-centered cubic high entropy alloys. Scr. Mater. 130, 96 (2017).

120. Z. Li, K.G. Pradeep, Y. Deng, D. Raabe, and C.C. Tasan: Metastable high-entropy dual-phase alloys overcome the strength-ductility trade-off. Nature 534, 227 (2016).

121. M.M. Wang, C.C. Tasan, D. Ponge, A.C. Dippel, and D. Raabe: Nanolaminate transformation-induced plasticity-twinninginduced plasticity steel with dynamic strain partitioning and enhanced damage resistance. Acta Mater. 85, 216 (2015).

122. F. He, Z. Wang, Q. Wu, J. Li, J. Wang, and C.T. Liu: Phase separation of metastable CoCrFeNi high entropy alloy at intermediate temperatures. Scr. Mater. 126, 15 (2017).

123. T. Egami, W. Guo, P.D. Rack, and T. Nagase: Irradiation resistance of multicomponent alloys. Metall. Mater. Trans. A 45, 180 (2014).
124. T. Nagase, S. Anada, P.D. Rack, J.H. Noh, H. Yasuda, H. Mori, and T. Egami: MeV electron-irradiation-induced structural change in the bcc phase of $\mathrm{Zr}-\mathrm{Hf}-\mathrm{Nb}$ alloy with an approximately equiatomic ratio. Intermetallics 38, 70 (2013).

125. M.A. Tunes, H. Le, G. Greaves, C.G. Schön, H. Bei, Y. Zhang, P.D. Edmondson, and S.E. Donnelly: Investigating sluggish diffusion in a concentrated solid solution alloy using ion irradiation with in situ TEM. Intermetallics 110, 106461 (2019).

126. Y. Zhang, T. Zuo, Y. Cheng, and P.K. Liaw: High-entropy alloys with high saturation magnetization, electrical resistivity, and malleability. Sci. Rep. 3, 1455 (2013).

127. P-K. Huang and J-W. Yeh: Inhibition of grain coarsening up to $1000{ }^{\circ} \mathrm{C}$ in (AlCrNbSiTiV)N superhard coatings. Scr. Mater. 62, 105 (2010)

128. S-Y. Chang, M-K. Chen, and D-S. Chen: Multiprincipal-element AlCrTaTiZr-nitride nanocomposite film of extremely high thermal stability as diffusion barrier for $\mathrm{Cu}$ metallization. $J$. Electrochem. Soc. 156, G37 (2009).

129. C.M. Rost, E. Sachet, T. Borman, A. Moballegh, E.C. Dickey, D. Hou, J.L. Jones, S. Curtarolo, and J-P. Maria: Entropystabilized oxides. Nat. Commun. 6, 8485 (2015).

130. A. Sarkar, R. Djenadic, N.J. Usharani, K.P. Sanghvi, V.S.K. Chakravadhanula, A.S. Gandhi, H. Hahn, and S.S. Bhattacharya: Nanocrystalline multicomponent entropy stabilized transition metal oxides. J. Eur. Ceram. Soc. 37, 747 (2017).

131. D. Bérardan, S. Franger, D. Dragoe, A.K. Meena, and N. Dragoe: Colossal dielectric constant in high entropy oxides. Phys. Status Solidi RRL 10, 328 (2016).

132. A. Sarkar, Q. Wang, A. Schiele, M.R. Chellali, S.S. Bhattacharya, D. Wang, T. Brezesinski, H. Hahn, L. Velasco, and B. Breitung High-entropy oxides: Fundamental aspects and electrochemical properties. Adv. Mater. 31, 1806236 (2019)

133. D. Bérardan, S. Franger, A.K. Meena, and N. Dragoe: Room temperature lithium superionic conductivity in high entropy oxides. J. Mater. Chem. A 4, 9536 (2016).

134. A. Sarkar, L. Velasco, D. Wang, Q. Wang, G. Talasila, L. de Biasi, C. Kübel, T. Brezesinski, S.S. Bhattacharya, H. Hahn, and B. Breitung: High entropy oxides for reversible energy storage. Nat. Commun. 9, 3400 (2018).

135. J. Chen, W.X. Liu, J.X. Liu, X.L. Zhang, M.Z. Yuan, Y.L. Zhao, J.J. Yan, M.Q. Hou, J.Y. Yan, M. Kunz, N. Tamura, H.Z. Zhang, and Z.L. Yin: Stability and compressibility of cationdoped high-entropy oxide $\mathrm{MgCoNiCuZnO}_{5}$. J. Phys. Chem. C 123, 17735 (2019).

136. H. Chen, J. Fu, P. Zhang, H. Peng, C.W. Abney, K. Jie, X. Liu, M. Chi, and S. Dai: Entropy-stabilized metal oxide solid solutions as $\mathrm{CO}$ oxidation catalysts with high-temperature stability. $J$. Mater. Chem. A 6, 11129 (2018).

137. J. Gild, M. Samiee, J.L. Braun, T. Harrington, H. Vega, P.E. Hopkins, K. Vecchio, and J. Luo: High-entropy fluorite oxides. J. Eur. Ceram. Soc. 38, 3578 (2018) 
138. S. Jiang, T. Hu, J. Gild, N. Zhou, J. Nie, M. Qin, T. Harrington, K. Vecchio, and J. Luo: A new class of high-entropy perovskite oxides. Scr. Mater. 142, 116 (2018).

139. R. Witte, A. Sarkar, R. Kruk, B. Eggert, R.A. Brand, H. Wende, and H. Hahn: High-entropy oxides: An emerging prospect for magnetic rare-earth transition metal perovskites. Phys. Rev. Mater. 3, 8 (2019).

140. J. Gild, Y. Zhang, T. Harrington, S. Jiang, T. Hu, M.C. Quinn, W.M. Mellor, N. Zhou, K. Vecchio, and J. Luo: High-entropy metal diborides: A new class of high-entropy materials and a new type of ultrahigh temperature ceramics. Sci. Rep. 6, 37946 (2016).

141. T.J. Harrington, J. Gild, P. Sarker, C. Toher, C.M. Rost,

O.F. Dippo, C. McElfresh, K. Kaufmann, E. Marin, L. Borowski, P.E. Hopkins, J. Luo, S. Curtarolo, D.W. Brenner, and

K.S. Vecchio: Phase stability and mechanical properties of novel high entropy transition metal carbides. Acta Mater. 166, 271 (2019).

142. J. Gild, J. Braun, K. Kaufmann, E. Marin, T. Harrington, P. Hopkins, K. Vecchio, and J. Luo: A high-entropy silicide: $\left(\mathrm{Mo}_{0.2} \mathrm{Nb}_{0.2} \mathrm{Ta}_{0.2} \mathrm{Ti}_{0.2} \mathrm{~W}_{0.2}\right) \mathrm{Si}_{2}$. J. Materiomics 5, 337 (2019).

143. R-Z. Zhang, F. Gucci, H. Zhu, K. Chen, and M.J. Reece: Datadriven design of ecofriendly thermoelectric high-entropy sulfides. Inorg. Chem. 57, 13027 (2018).
144. C. Heng, X. Huimin, D. Fu-Zhi, L. Jiachen, and Z. Yanchun: High entropy $\left(\mathrm{Yb}_{0.25} \mathrm{Y}_{0.25} \mathrm{Lu}_{0.25} \mathrm{Er}_{0.25}\right)_{2} \mathrm{SiO}_{5}$ with strong anisotropy in thermal expansion. J. Mater. Sci. Technol. 36, 134-139 (2019).

145. N. Zhou, S. Jiang, T. Huang, M. Qin, T. Hu, and J. Luo: Singlephase high-entropy intermetallic compounds (HEICs): Bridging high-entropy alloys and ceramics. Sci. Bull. 64, 856 (2019).

146. C. Suryanarayana, E. Ivanov, and V.V. Boldyrev: The science and technology of mechanical alloying. Mater. Sci. Eng., A 304306, 151 (2001).

147. G.E. Kim, V.K. Champagne, M. Trexler, and Y. Sohn: Processing nanostructured metal and metal-matrix coatings by thermal and cold spraying, Nanostructured Metals and Alloys-Processing, Microstructure, Mechanical Properties, and Applications, S.H. Wang, ed. (Woodhead Publishing Ltd., Cambridge, U.K., 2011); pp. 615-658

148. S. Swann: Magnetron sputtering. Phys. Technol. 19, 67 (1988).

149. U. Erb: Electrodeposited nanocrystals: Synthesis, properties and industrial applications. Nanostruct. Mater. 6, 533 (1995).

150. D.H. Xiao, P.F. Zhou, W.Q. Wu, H.Y. Diao, M.C. Gao, M. Song, and P.K. Liaw: Microstructure, mechanical and corrosion behaviors of $\mathrm{AlCoCuFeNi}-(\mathrm{Cr}, \mathrm{Ti})$ high entropy alloys. Mater. Des. 116, 438 (2017). 